\title{
A Comparison of Analytical Approaches for Wellbore Heat Transmission in Layered Formations
}

\author{
Yu-ShuWu \\ Earth Sciences Division \\ Lawrence Berkeley Laboratory \\ University of California \\ Berkeley, California 94720 \\ August 1988 \\ RESEARCH REPORT \\ Submitted in partial satisfaction of the \\ requirements for the degree of \\ MASTER OF SCIENCE IN ENGINEERING \\ in the \\ GRADUATE DIVISION \\ of the

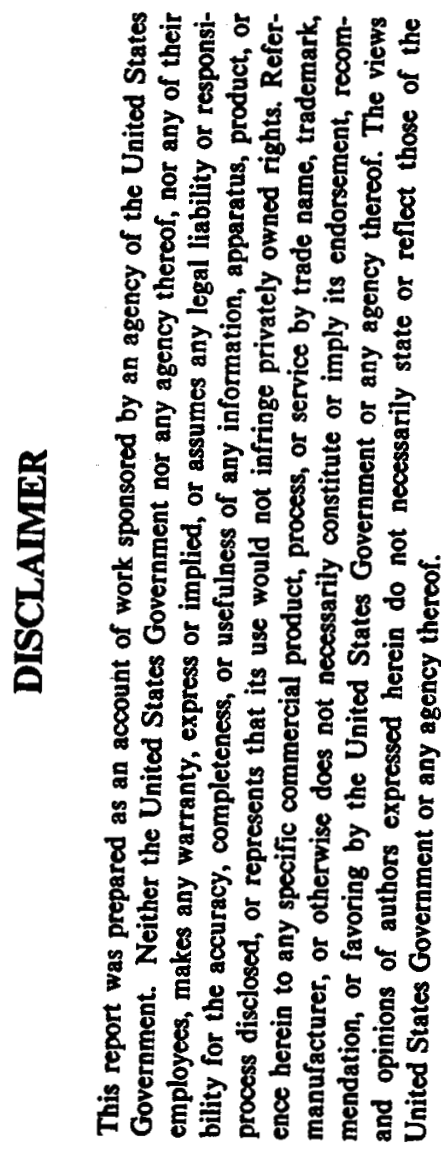 \\ UNIVERSITY OF CALIFORNIA AT BERKELEY
}

This work was supported by the U.S. Department of Energy under Contract No. DE-AC03-76SF00098.

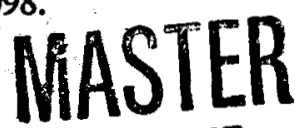




\section{DISCLAIMER}

This report was prepared as an account of work sponsored by an agency of the United States Government. Neither the United States Government nor any agency Thereof, nor any of their employees, makes any warranty, express or implied, or assumes any legal liability or responsibility for the accuracy, completeness, or usefulness of any information, apparatus, product, or process disclosed, or represents that its use would not infringe privately owned rights. Reference herein to any specific commercial product, process, or service by trade name, trademark, manufacturer, or otherwise does not necessarily constitute or imply its endorsement, recommendation, or favoring by the United States Government or any agency thereof. The views and opinions of authors expressed herein do not necessarily state or reflect those of the United States Government or any agency thereof. 


\section{DISCLAIMER}

Portions of this document may be illegible in electronic image products. Images are produced from the best available original document. 
1 


\section{Table of Contents}

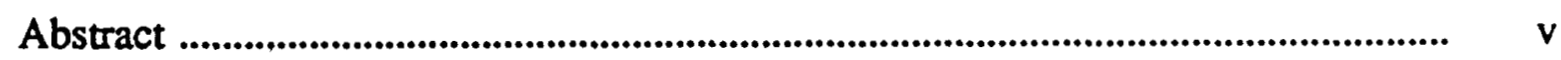

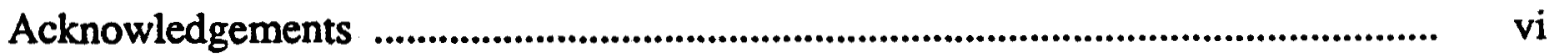

List of Figures ................................................................................................... vii

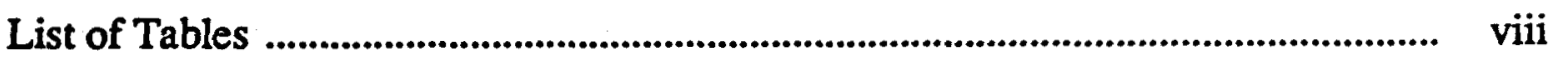

Nomenclature ............................................................................................................... ix

1. Introduction and Literature Review .................................................................

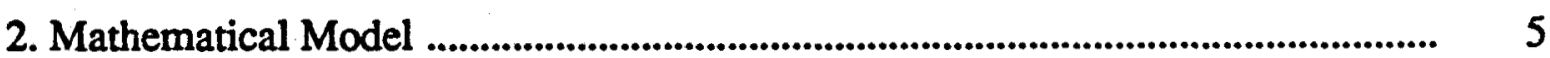

3. Analytical Solution ............................................................................. 7

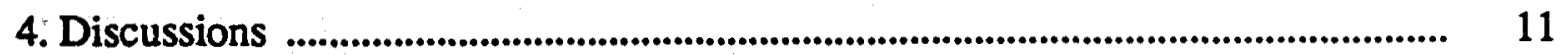

5. Summary and Conclusions ................................................................................ 22

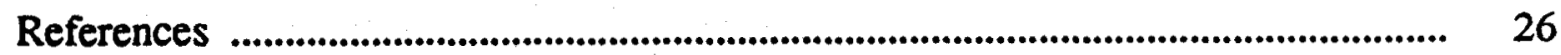

Appendix A: Development of Governing Equations ................................................... 28

Appendix B: Analytical Solution in Laplace Space .................................................... 32

Appendix C: Analytical Solution in Real Space ......................................................... 36

Appendix D: Heat Conduction Function of Thermal Resistance ................................. 41

Appendix E: Fortran Program for Calulation of Analytical Solutions ....................... 42 



\begin{abstract}
This report presents an analytical method for determining wellbore heat transmission during liquid or gas flow along the tubing. The mathematical model describes the heat transfer between the flowing fluid in the wellbore and in the surrounding formation as one whole physical system. The transient heat transfer equations in the two regions with coupling at the sandface are solved simultaneously. Previous treatments of wellbore heat transmission are improved upon in several aspects. Non-homogeneous formations are treated which consist of several layers with different physical properties and arbitrary initial temperature distributions in the vertical direction. Closed form analytical solutions are obtained in real space and in Laplace space, which can be used to calculate the temperature distribution along the wellbore and in the formation, and to evaluate heat transfer rate and cumulative heat exchange between wellbore and formation. A more accurate formula is given for the widely-used transient heat conduction function $f\left(t_{D}\right)$ of thermal resistance. This is shown to differ from Ramey's approximate solution at early time, while approaching it at very late time.
\end{abstract}




\section{Acknowledgements}

I would first like to express my deepest gratitude to my research advisor, Professor P. A. Witherspoon, for his guidance and support of this project, and for accepting me as a visiting researcher and into a graduate program at Berkeley, where I have had an opportunity to participate in the excellent research environment. I would also like to thank Dr. Karsten Pruess for his invaluable guidance and insight, consistent encouragement and critical review of this work. Without his help, the project would not have been completed. Special thanks to Prof. T. N. Narasimhan for his careful review and valuable suggestions of this work.

Many friends and colleagues at Lawrence Berkeley Laboratory have given me a lot of help and encouragement during this work. I am especially grateful to Ron Falta, Mark Ripperda, Peter Fuller, Scott Gaulke, Nora Okusu, and Chao Shan.

I am also grateful to Ellen Klahn and Diana Parks for their expert typing of the manuscript.

This work was funded by the U.S. Dept. of Energy, under Contract No. DEAC03-76SF00098. 


\section{List of Figures}

Figure 1 Schematic of the wellbore and its surroundings.

Figure 2 Heat transfer into a single homogeneous layer: Comparison of numerical inversion of Laplace transformation with exact solution and Ramey's solution (Ramey, 1962).

Figure 3 Single-layer case: Verification of numerical inversion of Laplace transformation with exact solution and Ramey's solution (Ramey, 1962).

Figure 4 Ratio of vertical and horizontal temperature gradients and temperature distribution in formation.

Figure 5 Discontinuity of vertical temperature on sandstone-clay interface.

Figure 6 Single-layer case: Comparison of steady-state and transient heat transfer in wellbore.

Figure 7 Effect of depth on $f\left(t_{D}\right)$.

Figure 8 Heat flux into formation.

Figure 9 Cumulative heat transfer into formation.

Figure 10 Wellbore temperature distribution of sandstone-clay 2-layer formation. Dashed lines indicate profiles for a single sandstone layer temperature.

Figure A-1 Schematic of Wellbore heat transfer

Figure C-1 Contour for evaluating Laplace transform 
- viii -

\section{List of Tables}

Table 1. Calculation Data 


\section{Nomenclature}

$A_{j}\left(t_{D}\right) \quad$ defined in (31)

$\bar{A}_{j}(s) \quad$ defined in (C-2)

$B_{j}\left(z_{D}, t_{D}\right) \quad$ defined in $(32)$

$\bar{B}_{j}\left(z_{D}, s\right) \quad$ defined in $(C-3)$

c effective specific heat of formation $\left[\mathrm{J} / \mathrm{kg} \cdot{ }^{\circ} \mathrm{C}\right]$

$c_{j}$ formation specific heat of layers $j\left[\mathrm{~J} / \mathrm{kg}{ }^{\circ} \mathrm{C}\right]$

$c_{\mathrm{t}}$ specific heat of wellbore fiuid $\left[\mathrm{J} / \mathrm{kg}{ }^{\circ} \mathrm{C}\right]$

$\mathrm{C}_{\mathrm{j}} \quad$ constant in (B.23, B.24)

$D_{j}(s) \quad$ defined in (B.25)

$D_{j}^{*}(u) \quad$ defined in $(C-15)$

c internal energy [J/kg]

$f\left(t_{D}\right) \quad$ transient heat conduction function, defined in (35)

$f_{j}\left(t_{D}\right) \quad$ defined in $(C-7)$

$\bar{f}_{\mathrm{j}}(\mathrm{s}) \quad$ defined in $(\mathrm{C}-2)$

g gravity acceleration $\left[\mathrm{m} / \mathrm{sec}^{2}\right]$

$g_{j}\left(r_{D}, t_{D}\right) \quad$ defined in $(C-12)$

$\overline{\mathrm{g}}_{\mathrm{j}}\left(\mathrm{r}_{\mathrm{D}}, \mathrm{s}\right) \quad$ defined in $(\mathrm{C}-6)$

$\mathrm{G}_{\mathrm{j}}(\mathrm{z}) \quad$ initial formation temperature as function of depth $\left[{ }^{\circ} \mathrm{C}\right]$

h enthalpy [J/kg]

H depth to top of permeable interval [m] 
$\mathrm{h}_{\mathrm{c}}$

$h_{t}$

$\mathrm{K}_{\mathrm{c}}$

$\mathrm{K}_{\text {cem }}$

$\mathbf{K}_{\mathbf{j}}$

$\mathrm{K}_{\mathrm{o}}$

$\mathrm{K}_{1}$

$\dot{\mathbf{m}}$

$\mathrm{N}$

$q^{\prime}$

$\mathrm{q}_{\mathrm{j}}^{\prime \prime}$

$\overrightarrow{\mathrm{q}}_{\mathbf{j}}^{\prime}(\mathrm{z}, \mathbf{s})$

Q

$Q_{\mathbf{c}}$

$\overline{\mathrm{Q}}_{\mathrm{c}}(\mathbf{s})$

$\mathbf{Q}_{\mathrm{t}}$

$\overline{\mathrm{Q}}_{\mathrm{t}}(\mathrm{s})$

$\mathbf{r}$

$\mathbf{r}_{\mathrm{D}}$ convective heat transfer coefficient of casing $\left[\mathrm{W} / \mathrm{m}^{2 \circ} \mathrm{C}\right]$

convective heat transfer coefficient of tubing $\left[\mathrm{W} / \mathrm{m}^{2 \circ} \mathrm{C}\right]$

defined in (27) - (29) $(j=1,2,3)$

zero-order Bessel function of the first kind

first-order Bessel function of the first kind

thermal conductivity $\left[\mathrm{W} / \mathrm{m}^{\circ} \mathrm{C}\right]$

thermal conductivity of casing wall $\left[\mathrm{W} / \mathrm{m}^{\circ} \mathrm{C}\right]$

thermal conductivity of cement $\left[\mathrm{W} / \mathrm{m}^{\circ} \mathrm{C}\right]$

thermal conductivity of layer $\mathrm{j}$ formation $\left[\mathrm{W} / \mathrm{m}^{\circ} \mathrm{C}\right]$

zero-order modified Bessel function of the second kind

first-order modified Bessel function of the second order

mass flow rate inside tubing $[\mathrm{kg} / \mathrm{sec}]$

total formation layer number with different physical properties

heat fiux between tubing and sandface $\left[\mathrm{W} / \mathrm{m}^{2}\right]$

heat flux between tubing and sandface in formation layer $j\left[\mathrm{~W} / \mathrm{m}^{2}\right]$

defined in (24)

injection rate $\left[\mathrm{m}^{3} / \mathrm{sec}\right]$

cumulative heat transfer between well and formation []

defined in (25)

total heat flux into the formation [W]

defined in (B-31)

radius [m]

dimensionless radius (11) 


\begin{tabular}{|c|c|}
\hline $\mathbf{r}_{\mathbf{w}}$ & outside radius of cement zone [m] \\
\hline $\mathbf{r}_{\mathbf{t}}$ & inside radius of tubing [m] \\
\hline $\mathbf{r}_{\mathbf{c}}$ & inside radius of casing [m] \\
\hline $\mathbf{R}_{\mathbf{j}}(\mathbf{u})$ & defined in $(C-14)$ \\
\hline s & Laplace transform variable \\
\hline $\mathbf{t}$ & time [sec] \\
\hline $\mathbf{T}$ & temperature $\left[{ }^{\circ} \mathrm{C}\right]$ \\
\hline $\mathrm{T}_{\mathrm{air}}$ & surface temperature $\left[{ }^{\circ} \mathrm{C}\right]$ \\
\hline $\mathrm{T}_{\mathrm{cj}}$ & constant temperature in $\mathrm{G}_{\mathrm{j}}(\mathrm{z})\left[{ }^{\circ} \mathrm{C}\right]$ \\
\hline$t_{D}$ & dimensionless time (12) \\
\hline$T_{\text {inj }}$ & surface injection fluid temperature $\left[{ }^{\circ} \mathrm{C}\right]$ \\
\hline $\mathrm{T}_{1 \mathrm{j}}(\mathbf{z}, \mathrm{t})$ & temperature along tubing $\left[{ }^{\circ} \mathrm{C}\right]$ \\
\hline$T_{2 j}(r, z, t)$ & temperature in formation $\left[{ }^{\circ} \mathrm{C}\right]$ \\
\hline $\mathbf{U}$ & overall heat transfer coefficient $\left[\mathrm{W} / \mathrm{m}^{2}{ }^{\circ} \mathrm{C}\right]$ \\
\hline $\mathbf{U}_{\mathbf{j}}$ & overall heat transfer coefficient between wellbore and formation layer $j$ \\
\hline & {$\left[\mathrm{W} / \mathrm{m}^{2}{ }^{\circ} \mathrm{C}\right]$} \\
\hline $\mathbf{v}$ & specific volume $\left[\mathrm{m}^{3} / \mathrm{kg}\right]$ \\
\hline $\mathrm{V}_{\mathrm{m}}$ & mean flow speed inside tubing $[\mathrm{m} / \mathrm{sec}]$ \\
\hline $\mathbf{Y}_{0}$ & zero-order Bessel function of the second kind \\
\hline $\mathbf{Y}_{1}$ & first-order Bessel function of the second kind \\
\hline $\mathbf{z}$ & vertical coordinate $[\mathrm{m}]$ \\
\hline $\mathbf{z}_{\mathrm{D}}$ & dimensionless vertical coordinate (13) \\
\hline$z_{j}$ & depth of bottom of layer; $\left(j=1,2 \ldots N, z_{0}=0\right)$ \\
\hline
\end{tabular}




\begin{tabular}{|c|c|}
\hline$z_{\mathrm{Dj}}$ & $z_{j} / H$, dimensionless of depth of layer $j(j=1,2, \ldots, N)$ \\
\hline$\alpha$ & thermal diffusivity $\left[\mathrm{m}^{2} / \mathrm{sec}\right]$ \\
\hline$\beta_{j}$ & dimensionless constant (B-3) \\
\hline$\gamma_{j}$ & geothermal gradient of layer $\mathrm{j}\left[{ }^{\circ} \mathrm{C} / \mathrm{m}\right]$ \\
\hline$\delta_{c}$ & thickness of casing wall $[\mathrm{m}]$ \\
\hline$\delta_{j}\left(z_{D}\right)$ & defined in (B-4) \\
\hline$\delta_{\mathfrak{t}}$ & thickness of tubing wall $[\mathrm{m}]$ \\
\hline$\theta_{j}\left(z_{D}, t_{D}\right)$ & dimensionless temperature functions of wellbore \\
\hline$\xi_{j}\left(z_{D}\right)$ & dimensionless function (B-5) \\
\hline$\rho$ & density $\left[\mathrm{kg} / \mathrm{m}^{3}\right]$ \\
\hline$\rho_{\mathbf{t}}$ & density of fluid $\left[\mathrm{kg} / \mathrm{m}^{3}\right]$ \\
\hline$\rho_{\mathbf{j}}$ & density of formation layer $\mathrm{j}\left[\mathrm{kg} / \mathrm{m}^{3}\right]$ \\
\hline$\sigma_{\mathbf{j}}$ & dimensionless constant (B-6) \\
\hline$\phi_{j}\left(r_{D}, z_{D}, t_{D}\right)$ & dimensionless temperature function of formation \\
\hline
\end{tabular}

\section{Subscripts}

$\begin{array}{ll}\text { C } & \text { casing } \\ \text { cem } & \text { cement } \\ \text { D } & \text { dimensionless } \\ \text { j } & \text { formation layer index }(\mathrm{j}=1,2, \ldots, \mathrm{N}) \\ \text { t } & \text { tubing } \\ 1 & \text { region } 1, \text { tubing } \\ 2 & \text { region } 2, \text { surroundings }\end{array}$




\section{Introduction}

Heat is transferred to or from the wellbore when there is a difference in temperature between the surrounding formation and the injected (or produced) fluid in the wellbore. In order to evaluate the feasibility of a thermal-recovery project, it is necessary to estimate the heat losses or gains of the flowing fluid in wellbores, the changes in temperature with time and depth, and the heat transfer conditions between wellbore and formation. A quantitative description of heat exchange between a wellbore and surrounding formations is also often required when one attempts to estimate formation temperatures from wellbore measurements.

Studies of wellbore heat transmission during hot or cold fluid injection have appeared in the literature since the 1950's. The techniques available at the present time for dealing with wellbore heat transmission include analytical and numerical methods. Lessem et al. ${ }^{[1]}$ and Squier et al. ${ }^{[2]}$ derived and solved similar systems of differential equations describing the temperature behavior of gas and hot water injection wells. They neglected wellbore thermal resistance and made the following assumptions:

1. There is no conductive heat transfer in the vertical direction of either the flowing fluid or the formation.

2. The mass flow rate of gas or water is constant throughout the injection or production system.

3. The volumetric heat capacities of fluids and formation are constant.

4. The formation is homogeneous and isotropic with constant thermal conductivity.

5. The fluid temperature and the formation temperature at the wellbore surface are equal.

All subsequent work introduced another approximation, namely, that vertical heat transfer in the wellbore was considered steady state. 
Moss and White ${ }^{[3]}$ derived a line-source expression for evaluation of the water temperature during hot water injection as a function of time. They assumed the following:

1. The physical properties of the fluid and the formation are independent of the depth and temperature.

2. No wellbore thermal resistance.

3. Negligible fractional losses and kinetic energy effects.

4. The heat transfer in the wellbore is considered steady state.

The classic study by Ramey ${ }^{[4]}$ on wellbore heat transmission improved Moss and White' $s{ }^{[2]}$ approach to incorporate an overall heat transfer coefficient. Ramey presented an approximate solution for the temperature of fluids, tubing and casing as a function of time and depth in a well used for hot-fiuid injection. He used similar assumptions to Moss and White's, which were (1) heat flows radially away from the wellbore, (2) steady-state heat loss in the wellbore, and (3) constant thermal and physical properties. Satter ${ }^{[5]}$ suggested a similar method for analyzing wellbore heat loss when taking into account condensing steam flow, and he provided a sample procedure for a given set of reservoir properties and a heat-loss correlation for estimating heat losses involved during injection of saturated steam. An expression for the overall heat transfer coefficient for any well completion and the early time values of the transient heat conduction function were given by Willhite ${ }^{[6]}$.

The more recent analytical work by Durrant et al. ${ }^{[7]}$ provided an iterative procedure for the wellbore heat transmission problem during flow of steam/water mixtures which includes vertical heat conduction. They also employed the assumption of steady-state heat transfer in the wellbore. The mathematical model they used combined Ramey's approach and Farouq Ali's ${ }^{[8]}$ numerical model. The analytical treatment of the twodimensional heat conduction equation in a homogeneous and isotropic formation permitted a simple supposition algorithm in the time domain. 
The numerical models for wellbore heat transmission by Farouq $\mathrm{Ali}^{[8]}$ and Wooley ${ }^{[9]}$ were more comprehensive than the analytical models. They included both horizontal and vertical heat conduction in the formation, and were able to deal with different well operation conditions. Farouq Ali's wellbore model is one of the most sophisticated models that can simulate vertical, nonisothermal two phase flow phenomenon to account for the slip concept and flow regimes, but the assumption that the heat transfer in the wellbore is steady-state is still inherent in his model. Even though numerical models can take into account more physical properties and can simulate a more complex wellbore heat transmission system, they are often too complicated for field application or for reservoir simulation studies since many of the wellbore and formation heat transfer properties needed in modeling are rarely known precisely.

The mathematical model for wellbore heat transmission presented in this paper adopts assumptions similar to those of Lessem, et al..$^{[1]}$ The main differences are that an overall heat transfer coefficient is introduced to consider the wellbore heat resistance and that non-homogeneous formations are approximated as a multiple-layer system (see Figure 1). The solution provided in the report for wellbore heat transfer is similar to that of Lessem et al. ${ }^{[1]}$ and Ramey ${ }^{[4]}$, with the following extensions and improvements:

1. The partial differential equations of fully transient heat transfer between well fluid and formation are solved simultaneously by incorporating an overall heat transfer coefficient. Heat transfer in the wellbore is treated as fully transient.

2. The inhomogeneous formation is approximated as multiple horizontal layers with different physical properties. Initial temperature distribution in the vertical direction for each layer can be arbitrary.

3. Exact solutions for wellbore temperatures and heat transfer rate are obtained in both real space and in Laplace space. The solutions are valid for the entire time range, from early to late.

4. A more accurate formula is given for the widely-used transient heat conduction function $f\left(t_{D}\right)$ of thermal resistance. $f\left(t_{D}\right)$ is found to be a function not only of time but also of depth. 


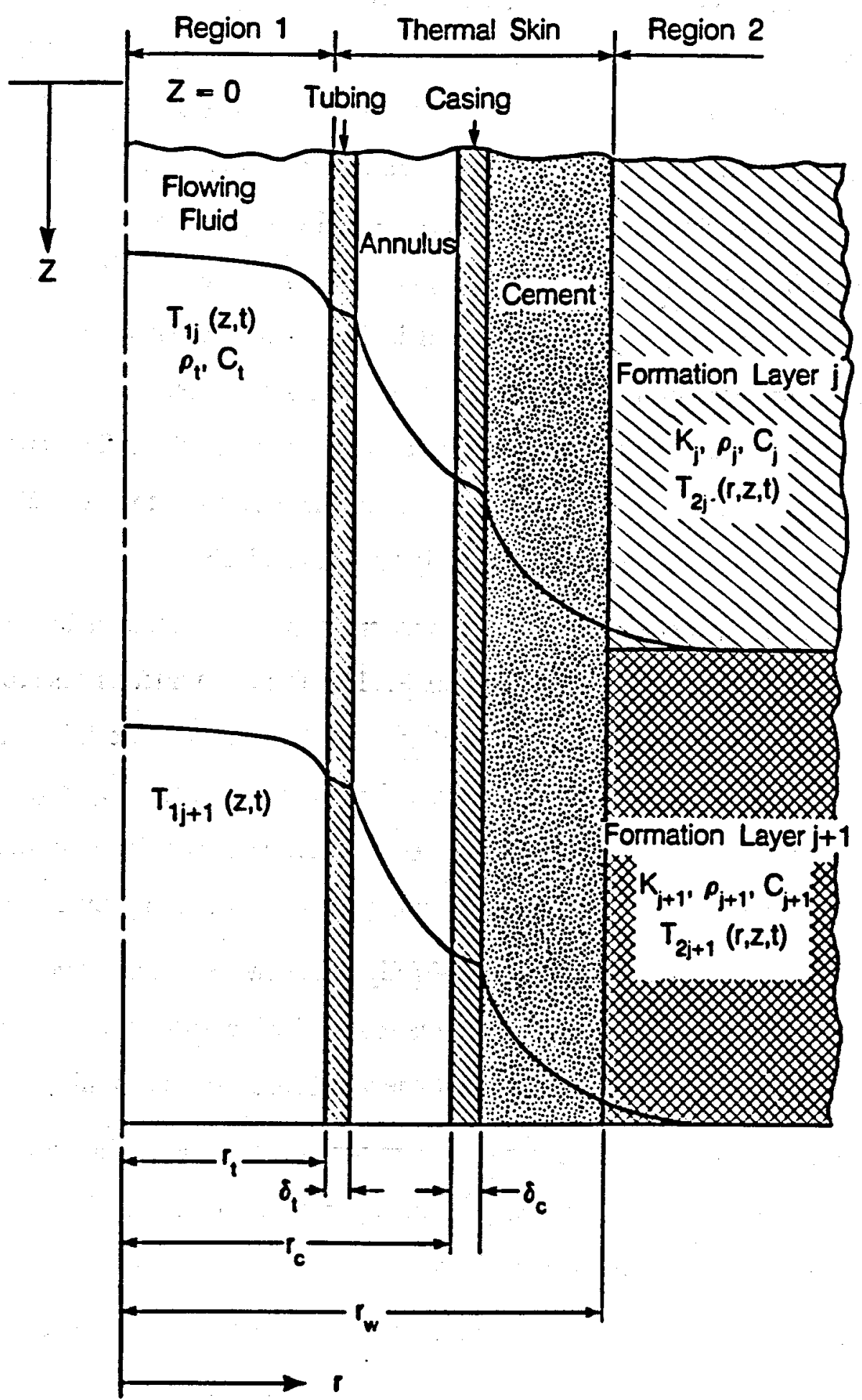

XBL 882-10052

Figure 1 Schematic of the wellbore and its surroundings. 
The numerical results calculated from the analytical solutions are compared with Ramey's long time approximation. Illustrative applications are given for predicting wellbore heat transmission for engineering designs or reservoir simulation studies in petroleum and geothermal reservoir development.

\section{Mathematical Model}

The transient heat transmission problem under consideration is as follows (see Figure 1):

The injection (or production) well is cased to the top of the injection (or production) interval. Heat is transferred along the wellbore solely by convection and then by conduction into formation. The formation consists of $\mathrm{N}$ layers with different thermal and physical properties. The system to be modeled is composed of three parts, as shown in Figure 1, (i) fluid flow conduit inside the tubing; (ii) tubing/casing annulus, casing wall and cement; (iii) infinite formation surrounding the casing. The major assumptions and approximations are as follows:

1. well mass flow rate is constant;

2. fluid flow in the tubing is one-dimensional;

3. the well fluid temperature is lumped radially;

4. the heat conduction in the vertical direction is neglected compared with heat convection by the flowing fluid;

5. radial heat flow between the wellbore and the formation is steady state;

6. in the surrounding earth, the initial geothermal gradient is a known function of depth; and,

7. the vertical heat conduction in the horizontal-layered formation can be ignored compared with the horizontal heat conduction. 
All the other assumptions are similar to those of the previous workers. Therefore, the heat transfer equation in the tubing can be written as (see Appendix A): for liquid flow,

$$
\begin{gathered}
\rho_{\mathrm{t}} c_{\mathrm{t}} \frac{\partial T_{1 j}}{\partial t}+\frac{2}{r_{\mathrm{t}}} q_{j}^{\prime \prime}+\rho_{\mathrm{t}} c_{\mathrm{t}} V_{m} \frac{\partial T_{1 j}}{\partial z}=0 \\
(j=1,2, \ldots N) \quad\left(z_{j-1}<z<z_{j}\right)
\end{gathered}
$$

for gas flow,

$$
\begin{gathered}
p_{\mathrm{t}} c_{\mathrm{t}} \frac{\partial T_{1 j}}{\partial t}+\frac{2}{r_{\mathrm{t}}} q_{j}^{\prime \prime}+p_{\mathrm{t}} c_{\mathrm{t}} V_{m}\left(\frac{\partial T_{1 j}}{\partial z} \pm \frac{g}{c_{\mathrm{t}}}\right)=0 \\
(j=1,2, \ldots, N)\left(z_{j-1}<z<z_{j}\right)
\end{gathered}
$$

where the plus sign on the potential energy term is used for flow down the well and the negative sign is used for flow up the well. ${ }^{[4]}$

The heat conduction in layer $j$ of the formation is described by

$$
\begin{aligned}
& \frac{1}{r} \frac{\partial}{\partial r}\left(r K_{j} \frac{\partial T_{2 j}}{\partial r}\right)=\rho_{j} c_{j} \frac{\partial T_{2 j}}{\partial t} \\
& (j=1,2, \ldots N) \quad\left(z_{j-1}<z<z_{j}\right)
\end{aligned}
$$

The heat flux at the tubing surface $\left(r=r_{t}\right)$ is:

$$
q_{j}^{\prime \prime}=U_{j}\left[T_{1 j}-\left.T_{2 j}\right|_{I=s_{w}}\right]
$$

and the overall heat transfer coefficient is defined by: ${ }^{[6]}$

$$
\begin{aligned}
& U_{j}=\left[\frac{1}{h_{t}}+\frac{r_{t} \ln \frac{r_{t}+\delta_{t}}{r_{t}}}{K_{t}}+\frac{r_{t}}{\left(r_{t}+\delta_{f}\right) h_{c}}+\frac{r_{t}}{r_{c} h_{c}}+\right. \\
& \left.\frac{r_{t} \ln \frac{r_{c}+\delta_{c}}{T_{c}}}{K_{c}}+\frac{r_{t} \ln \frac{r_{w}}{r_{c}+\delta_{c}}}{K_{c e m}}\right]_{j}^{-1}
\end{aligned}
$$

The initial conditions are: 
in the well,

$$
\begin{gathered}
T_{1 j}(z, t=0)=G_{j}(z) \text { (known functions) } \\
(j=1,2, \ldots N)\left(z_{j-1}<z \leq z_{j}\right)
\end{gathered}
$$

and in the formation,

$$
\begin{gathered}
T_{2 j}(r, z, t=0)=G_{j}(z) \\
j=1,2, \ldots N)\left(z_{j-1} \leq z \leq z_{j}\right)
\end{gathered}
$$

It is required in (6) and (7),

$$
G_{1}(0)=T_{\text {air }} \text { (constant) }
$$

The boundary conditions are:

$$
T_{11}(z=0, t)=T_{i n j}
$$

and

$$
\begin{aligned}
& \lim _{r \rightarrow \infty} T_{2 j}(r, z, t)=G_{j}(z) \\
& (j=1,2, \ldots N)
\end{aligned}
$$

\section{Analytical Solution}

Define the following dimensionless parameters for radial distance, time and depth:

$$
\begin{aligned}
& r_{D}=\frac{r}{r_{w}} \\
& t_{D}=\frac{t V_{m}}{H} \\
& z_{D}=\frac{z}{H}
\end{aligned}
$$

The dimensionless temperatures in wellbore and formation are:

$$
\theta_{j}\left(z_{D}, t_{D}\right)=\frac{T_{1 j}(z, t)-G_{j}(z)}{T_{i n j}-T_{a i r}}
$$




$$
\begin{gathered}
(j=1,2, \ldots N) \\
\phi_{j}\left(r_{D}, z_{D}, t_{D}\right)=\frac{T_{2 j}(r, z, t)-G_{j}(z)}{T_{i n j}-T_{a i r}} \\
(j=1,2, \ldots N)
\end{gathered}
$$

The unsteady-state solution of this system in Laplace space becomes (see Appendix B)

$$
\begin{gathered}
\bar{\theta}_{j}\left(z_{D}, s\right)=C_{j}(s) \exp \left[-\left[s+\beta_{j}-D_{j}(s)\right] z_{D}\right]+Y_{j}\left(z_{D}, s\right) \\
(j=1,2, \ldots N)
\end{gathered}
$$

where

$$
\begin{gathered}
C_{1}(s)=\frac{1}{s}+\frac{\delta_{1}\left(z_{D}\right)}{s\left(s+\beta_{1}-D_{1}(s)\right)} \\
C_{j}(s)=\left[\bar{\theta}_{j-1}\left(z_{D_{j-1}}, s\right)+\frac{\delta_{j}\left(z_{D}\right)}{s\left(s+\beta_{j}-D_{j}(s)\right)}\right] \exp \left[\left[s+\beta_{j}-D_{j}(s)\right] z_{D_{j-1}}\right] \\
(j=2,3, \ldots N)
\end{gathered}
$$

and

$$
\begin{gathered}
\bar{\phi}_{j}\left(r_{D}, z_{D}, s\right)=\frac{\omega_{j} \bar{\theta}_{j}\left(z_{D}, s\right) K_{o}\left(\sqrt{\sigma_{j} s} r_{D}\right)}{\omega_{j} K_{o}\left(\sqrt{\sigma_{j} s}\right)+\sqrt{\sigma_{j} s} K_{1}\left(\sqrt{\sigma_{j} s}\right)} \\
(j=1,2, \ldots N)
\end{gathered}
$$

The functions $Y_{j}(z, s), D_{j}(s)$, and $\delta_{j}\left(z_{D}\right)$ and the parameters $\beta_{j}, \omega_{j}$ and $\sigma_{j}$ are defined in Appendix $B$. The temperature function $\bar{\theta}_{j}$ in Laplace space can be determined recursively from layer $j=n$ to $n+1$ (going downwards; $n=1,2, \ldots, N-1$ ) since it is assumed that there is no vertical heat conduction both in the wellbore and in the formation. Therefore, downstream wellbore fluid temperature or formation temperature does not have any effect on upstream ones.

Another important variable of interest for wellbore heat transmission is the rate at which heat is transferred into (or from) the formation. For the case of a linear initial temperature distribution within each layer of the formation: 


$$
G_{j}(z)=T_{c j}+\gamma_{j} z
$$

where $T_{c j}$ are constants. Now the continuity at the interfaces of layers requires that

$$
T_{c l}=T_{\text {air }}
$$

and

$$
\begin{gathered}
T_{c j}+\gamma_{j} z_{j}=T_{c j+1}+\gamma_{j+1} z_{j} \\
(j=1,2, \ldots N-1)
\end{gathered}
$$

Then

$$
\begin{gathered}
G_{j}^{\prime}(z)=\gamma_{j} \quad \text { (constant) } \\
Y_{j}\left(z_{D}, s\right)=-\frac{\delta_{j}}{s\left(s+\beta_{j}-D_{j}(s)\right)} \quad \text { (constant) }
\end{gathered}
$$

For the heat flux into (or from) the formation we have the following expression in Laplace space:

$$
\begin{gathered}
\vec{q}_{j}^{\prime}(z, s)=-U_{j}\left(T_{i n j}-T_{i i r}\right)\left[\bar{\phi}_{j}\left(1, z_{D} s\right)-\bar{\theta}_{j}\left(z_{D}, s\right)\right] \\
(j=1,2, \ldots N)
\end{gathered}
$$

The cumulative heat flow rate is

$$
\bar{Q}_{c}(s)=\frac{H \bar{Q}_{\mathrm{r}}(s)}{s V_{m}}
$$

where $\bar{Q}_{t}(s)$ is defined in Equation (B.31).

The above solutions in Laplace space can be evaluated by numerical inversion techniques ${ }^{[10]}$. However, analytical solutions in real space are desirable for validating the numerical inversion results and for predicting the early-time transient behavior of the system since the numerical Laplace transform cannot be expected to give accurate results for early time. In this work, solutions in real space for the case of a linear initial temperature distribution in each layer in the formation have been obtained (see Appendix C). For layer $1\left(0 \leq z_{D} \leq z_{D 1}\right)$ or for a homogeneous formation we have, 


$$
\theta_{1}\left(z_{D}, t_{D}\right)= \begin{cases}I_{1} & \left(t_{D} \leq z_{D}\right) \\ I_{1}+I_{2}+I_{3} & \left(t_{D}>z_{D}\right)\end{cases}
$$

where

$$
\begin{aligned}
& I_{1}=\frac{4 \delta_{1}}{\pi^{2}} \int_{0}^{\infty} \frac{D_{1}^{*}(u)}{u} \frac{\left[\exp \left(-\frac{u^{2}}{\sigma_{1}} t_{D}\right)-1\right]}{\left\{\left[D_{1}^{*}(u)\left(\beta_{1}-\frac{u^{2}}{\sigma_{1}}\right)-R_{1}(u)\right]^{2}+\frac{4}{\pi^{2}}\right\}} d u \\
& I_{2}=\frac{2 e^{-\beta_{1} z_{D}}}{\pi} \int_{0}^{\infty} \frac{\left\{1-\exp \left[-\frac{u^{2}}{\sigma_{1}}\left(t_{D}-z_{D}\right)\right]\right\}}{u} \\
& \cdot \exp \left[z_{D} R_{1}(u) / D_{1}^{*}(u)\right] \sin \left[\frac{2 z_{D}}{\pi D_{1}^{*}(u)}\right] d u \\
& I_{3}=\frac{2 \delta_{1} e^{-\beta_{1} z_{D}}}{\pi} \int_{0}^{\infty} \frac{D_{1}^{*}(u)\left\{1-\exp \left(-\frac{u^{2}}{\sigma_{1}}\left(t_{D}-z_{D}\right)\right\}\right.}{u\left[D_{1}^{*}(u)\left(\beta_{1}-\frac{u^{2}}{\sigma_{1}}-R(u)\right]^{2}+\frac{4}{\pi^{2}}\right\}} . \\
& \cdot \exp \left[z_{D} R_{1}(u) / D_{1}^{*}(u)\right]\left\{\frac{2}{\pi} \cos \left[\frac{2 z_{D}}{\pi D_{1}^{*}(u)}\right]+\sin \left[\frac{2 z_{D}}{\pi D_{1}^{*}(u)}\right]\right. \\
& \left.\cdot\left[D_{1}^{*}(u)\left(\beta_{1}-\frac{u^{2}}{\sigma_{1}}\right)-R_{1}(u)\right]\right\} d u
\end{aligned}
$$

For layer $j=2,3, \ldots N$, the dimensionless wellbore temperatures are:

$$
\begin{gathered}
\theta_{j}\left(z_{D}, t_{D}\right)=A_{j}\left(t_{D}\right)+\int_{0}^{D}\left[\theta_{j-1}\left(z_{D j-1}, \tau\right)\right. \\
\left.-A_{j}(\tau)\right] B_{j}\left(z_{D}, t_{D}-\tau\right) d \tau
\end{gathered}
$$

where

$$
A_{j}\left(t_{D}\right)=\frac{4 \delta_{j}}{\pi^{2}} \int_{0}^{\infty} \frac{D_{j}^{*}(u)}{u} \frac{\left\{\exp \left(-\frac{u}{\sigma_{1}} t_{D}\right)-1\right\}}{\left\{\left[D_{j}^{*}(u)\left(\beta_{j}-\frac{u^{2}}{\sigma_{j}}\right)-R_{j}(u)\right]^{2}+\frac{4}{\pi^{2}}\right\}} d u
$$




$$
\begin{gathered}
B_{j}\left(z_{D}, t_{D}\right)=\left\{\begin{array}{l}
0 \quad\left(t_{D} \leq z_{D}-z_{D j-1}\right) \\
\frac{2}{\pi \sigma_{j}} \exp \left[-\beta_{j}\left(z_{D}-z_{D j-1}\right)\right] \int_{0}^{\infty} u \sin \left[\frac{2\left(z_{D}-z_{D j-1}\right)}{\pi D_{j}^{*}(u)}\right] \\
\cdot \exp \left[\left(z_{D}-z_{D j-1}\right) R_{j}(u) / D_{j}^{*}(u)-\frac{u^{2}}{\sigma_{j}}\left(t_{D}-z_{D}+z_{D j-1}\right)\right] d u \\
\left(t_{D}>z_{D}-z_{D j-1}\right)
\end{array}\right.
\end{gathered}
$$

In Equations (27)-(32), $R_{j}(u)$ and $D_{j}^{*}(u)$ are defined in Appendix $C$. The dimensionless temperature function in the formation layer $j$ is given by

$$
\phi_{j}\left(r_{D}, z_{D}, t_{D}\right)=\int_{0}^{t_{D}} \theta_{j}\left(z_{D}, \tau\right) g_{j}\left(r_{D}, t_{D}-\tau\right) d \tau
$$

where

$$
\begin{gathered}
g_{j}\left(I_{D}, t_{D}\right)=\frac{2}{\pi \sigma_{j} \beta_{j}} \int_{0}^{\infty} \frac{u}{D_{j}^{*}(u)} \exp \left(-\frac{u^{2}}{\sigma_{j}} t_{D}\right) \\
\cdot\left\{Y_{0}\left(u_{D}\right)\left[\omega_{j} J_{0}(u)+u J_{1}(u)\right]-J_{0}\left(u_{D}\right)\left[u Y_{1}(u)+\omega_{j} Y_{0}(u)\right]\right\} d u
\end{gathered}
$$

\section{Discussion}

To validate the analytical solutions, a series of tests have been run. The numerical inversion results of the Laplace transformed solution of Equation (16) have been compared with the numerical integration of the exact solution of Equation (26) and also with Ramey's late-time solution. The integrals appearing in Equation (26) were calculated with the numerical integral evaluation routine from the NAG Fortran Library, ${ }^{[11]}$ on a CRAY computer. Convergence was very rapid and smooth (Fortran program see Appendix E). 
Table 1. Calculation Data

$g_{g}=0.03^{\circ} \mathrm{C} / \mathrm{m}\left(0.016^{\circ} \mathrm{F} / \mathrm{ft}\right)$

$T_{\text {inj }}=100^{\circ} \mathrm{C}\left(212^{\circ} \mathrm{F}\right)$

$\mathrm{Q}=100 \mathrm{~m}^{3} /$ day $\left(3531 \mathrm{ft}^{3} /\right.$ day $)$

$P_{w}=958 \mathrm{~kg} / \mathrm{m}^{3}\left(59.8 \mathrm{lb} / \mathrm{ft}^{3}\right)$

$\mathrm{U}=978 \mathrm{~W} / \mathrm{m}^{2 \circ} \mathrm{C}\left(172 \mathrm{Btu} / \mathrm{ft}^{2} \mathrm{hr}{ }^{\circ} \mathrm{F}\right)$

Sandstone

$\rho=2200 \mathrm{~kg} / \mathrm{m}^{3}\left(137.3 \mathrm{lb} / \mathrm{gt}^{3} \mathrm{ft}^{3}\right)$

$\mathrm{c}=740 \mathrm{~J} / \mathrm{kg}^{\circ} \mathrm{C}\left(0.167 \mathrm{Btu} / \mathrm{b}_{\mathrm{m}}{ }^{\circ} \mathrm{F}\right)$

Clay

$\rho=1500 \mathrm{~kg} / \mathrm{m}^{3}\left(93.6 \mathrm{lb} / \mathrm{m}^{3}\right)$

$\mathrm{c}=800 \mathrm{~J} / \mathrm{kg}^{\circ} \mathrm{C}\left(0.191 \mathrm{Btu} / \mathrm{h}_{\mathrm{m}}{ }^{\circ} \mathrm{F}\right)$
$\mathrm{T}_{\text {iir }}=20^{\circ} \mathrm{C}\left(68^{\circ} \mathrm{F}\right)$

$D=1000 \mathrm{~m}(3281 \mathrm{ft})$

$r_{w}=0.08 \mathrm{~m}(0.26 \mathrm{ft})$

(6.33 in ID)

$c_{w}=4196 \mathrm{~J} / \mathrm{kg} \cdot{ }^{\circ} \mathrm{C}\left(1.00 \mathrm{Btu} / \mathrm{lb}_{\mathrm{m}}{ }^{\circ} \mathrm{F}\right)$

$\mathrm{K}=2.8 \mathrm{~W} / \mathrm{m}^{\circ} \mathrm{C}\left(1.62 \mathrm{Btu} / \mathrm{ft} \mathrm{hr}{ }^{\circ} \mathrm{F}\right)$

$\mathrm{K}=1.4 \mathrm{~W} / \mathrm{m}^{\circ} \mathrm{C}\left(0.81 \mathrm{Btu} / \mathrm{ft} \mathrm{hr}{ }^{\circ} \mathrm{F}\right)$ 
The example problem involving a hot-water injection at a constant rate. The fluid and formation data for the calculation is given in Table 1. Figures present results for a single layer case and compare the present work with that of Ramey (1962). As shown in Figure 2, the numerical Laplace inversion results are in perfect agreement with the exact solution, and at long times, both the solutions and Ramey's solution converge to the same curve.

The results from the numerical Laplace inversion by the Stehfest algorithm generally need checking against some other solution, in particular for early times. The comparison of the numerical Laplace inversion with the exact solution of Equation (26) and Ramey's approximate solution is given in Figure 3. It is obvious that the numerical inversion gives very poor results for $t_{D} \leq z_{D}$. This probably occurs because of the rapidly changing condition at the sandface, which is discontinuous along the wellbore until the entire wellbore is full of injected water when $t_{D}>1$. Physically, $z_{D}>t_{D}$ means that the injected fluid has not reached the dimensionless depth $z_{D}$ and the temperature there is not disturbed. When the time is a little longer, the numerical inversion will give very accurate results. Therefore, instead of the analytical solutions in the Laplace space, the exact solution in the real space should be used for applications in which the very early time transient behavior is important, such as in temperature well logging analysis. $^{\text {[12] }}$

As in most studies on wellbore heat transfer, the vertical heat conduction is ignored here, in comparison with horizontal flow. We examine this approximation by comparing the horizontal and vertical temperature gradients in the formation derived from the solutions obtained above. As shown in Figure 4, the ratio of vertical and horizontal temperature gradients is always smaller than $1 \%$, and reaches its maximum around the temperature penetration fronts. A larger vertical heat flow may occur on the interface of formation layers with different properties, where the temperatures obtained by neglecting vertical flow are vertically discontinuous. Figure 5 shows that despite rather different thermal diffusivities $\left(\mathrm{K} / \mathrm{pc}=1.72 \mathrm{E}-6 \mathrm{~m}^{2} / \mathrm{s}\right.$ for sandstone, $1.17 \mathrm{E}-6 \mathrm{~m}^{2} / \mathrm{s}$ for clay), the difference in temperatures is very small on the interface of sandstone and clay whose 


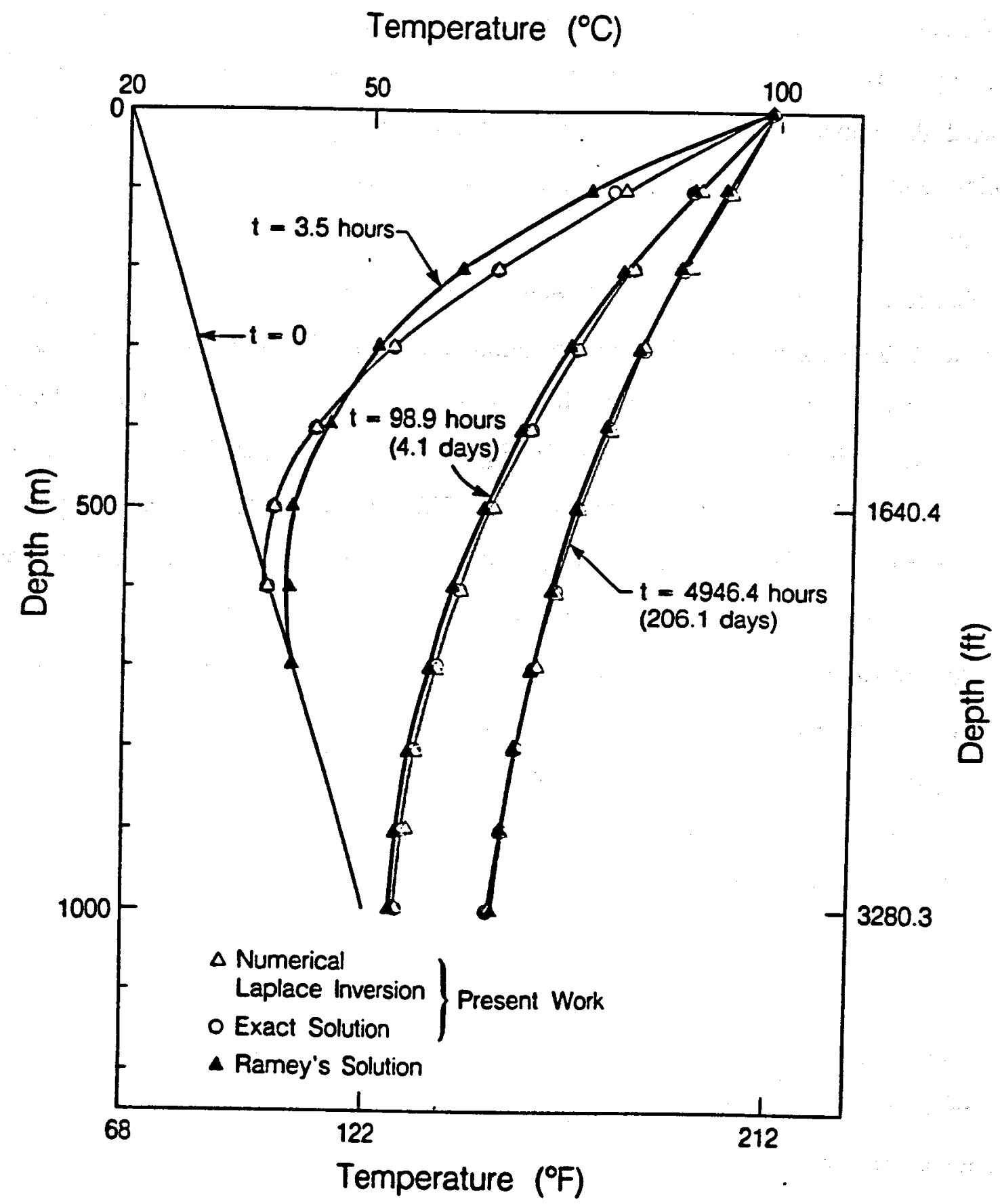

XBL $882 \cdot 10050$

Figure 2 Heat transfer into a single homogeneous layer: Comparison of numerical inversion of Laplace transformation with exact solution and Ramey's solution (Ramey, 1962). 


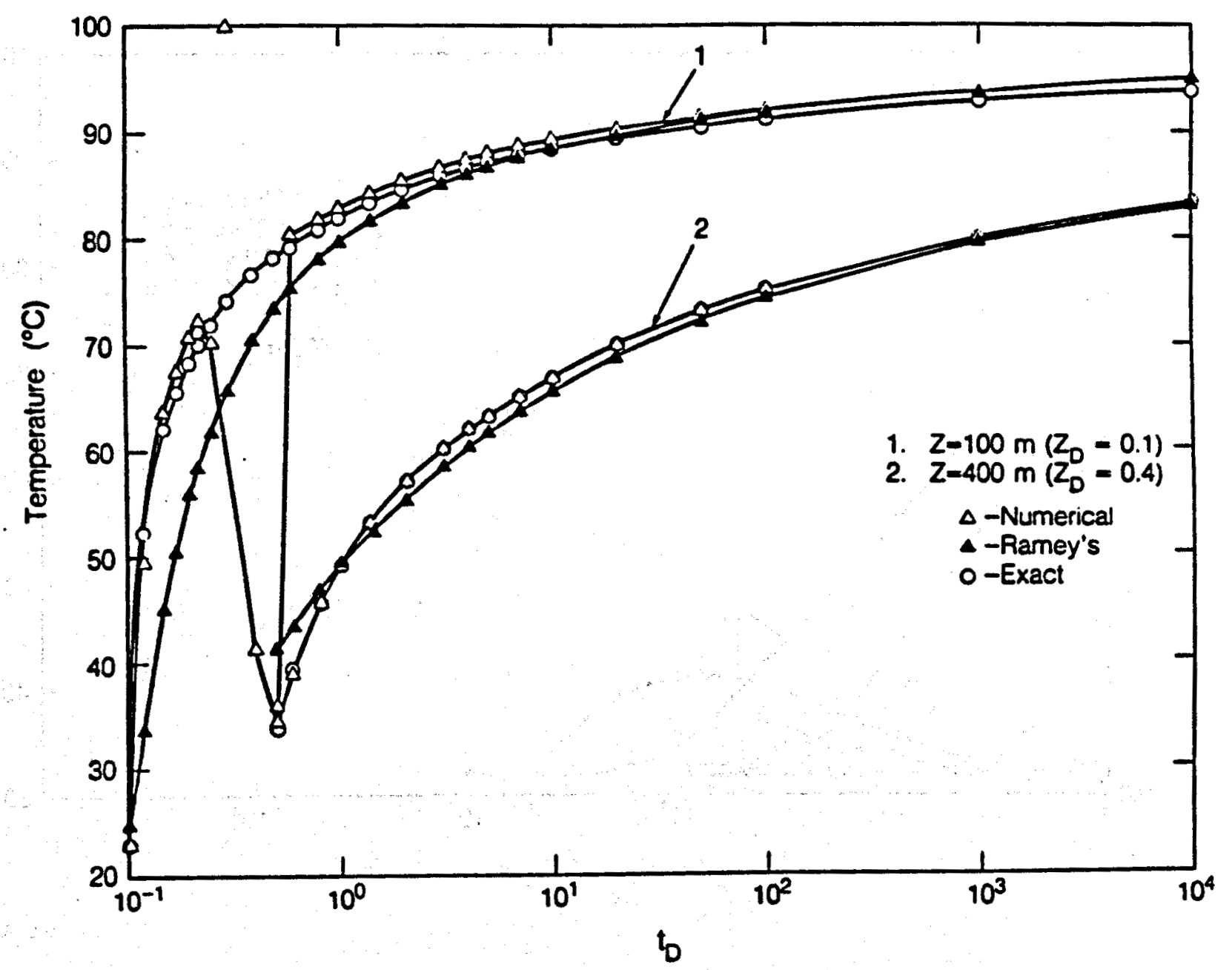

$\times B L 682 \cdot 10097$

Figure 3 Single-layer case: Verification of numerical inversion of Laplace transformation with exact solution and Ramey's solution (Ramey, 1962). 


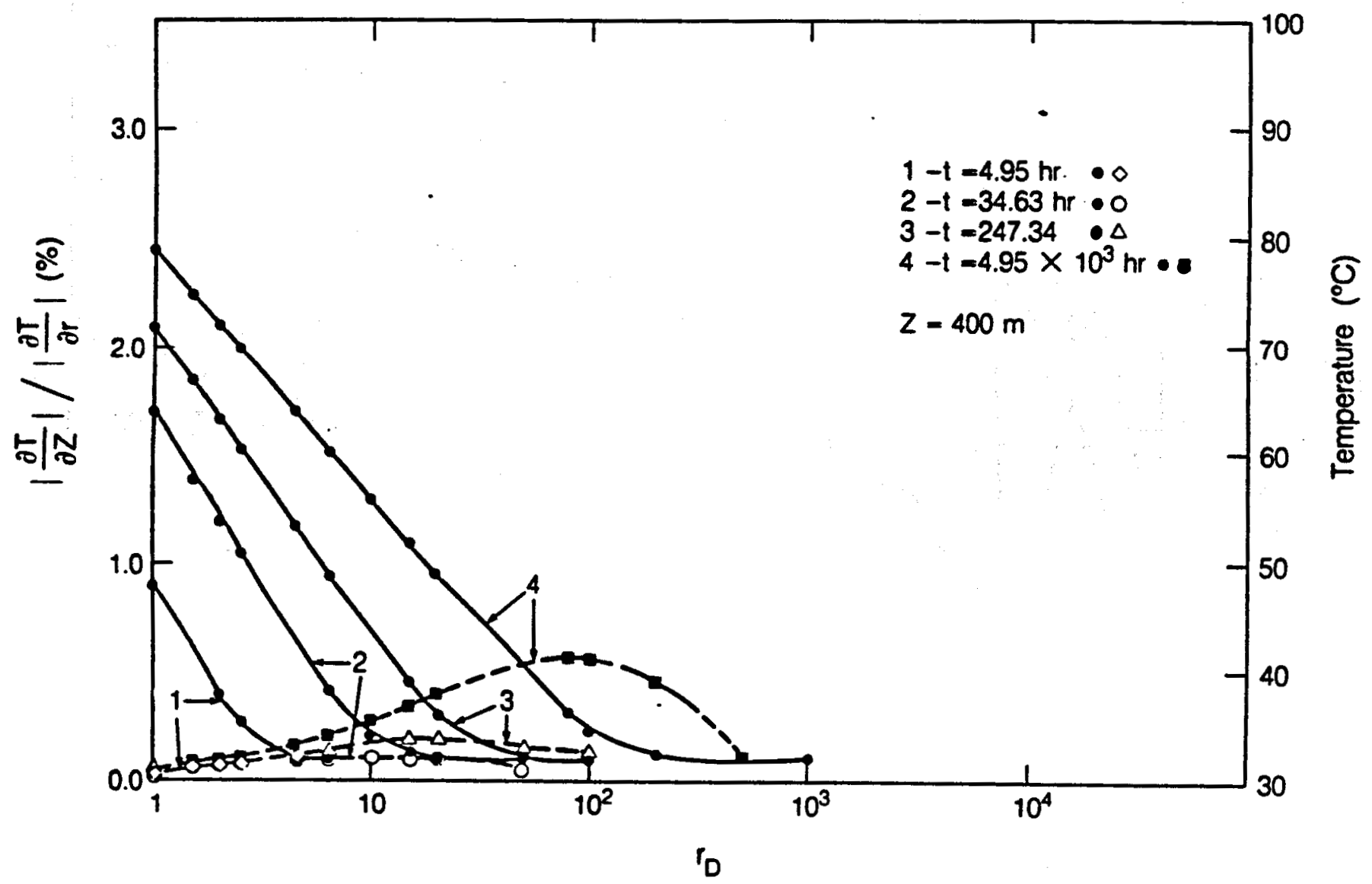

XBL $882 \cdot 10098$

Figure 4 Ratio of vertical and horizontal temperature gradients and temperature distribution in formation. 


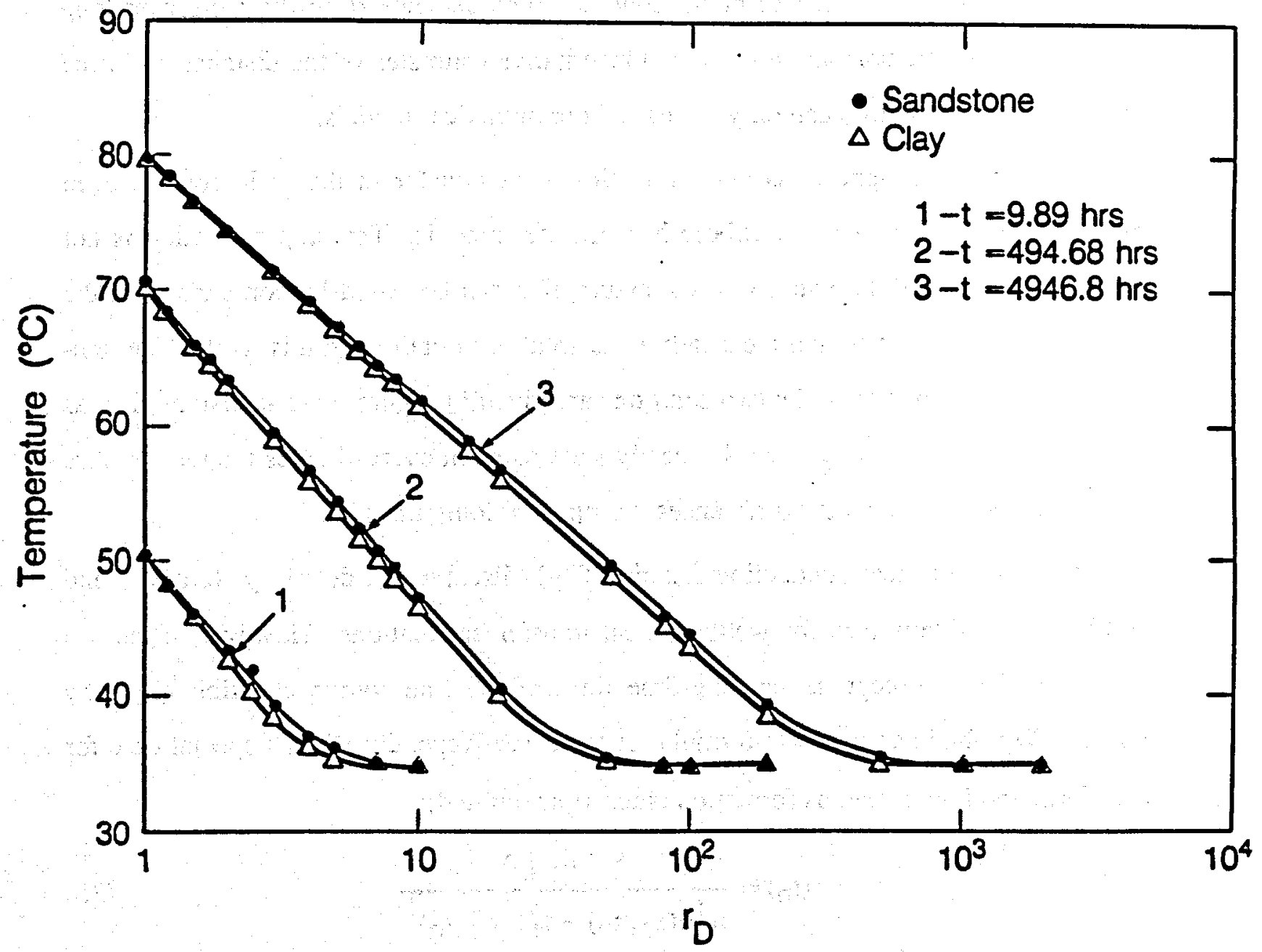

XBL 882-10202

Figure 5 Discontinuity of vertical temperature on sandstone-clay interface. 
properties are given in Table 1. These results should be conservative because vertical temperature differences are overestimated by neglecting the vertical flow. Therefore, the assumption that the vertical heat flow in the formation is negligible is probably acceptable for most engineering applications. The approximation of neglecting vertical heat flow in the formation will break down at some distance from the well after long times for non-homogeneous reservoirs. Quantitative estimates of the distance and time limits for its applicability can only be made from numerical models.

A steady-state approximation for vertical heat transfer in the wellbore has been made in almost all previous wellbore heat transfer models. This approximation is not resorted to here, and the validity of the assumption can be tested by comparison of the results from the transient and the steady-state solutions obtained in this work. The temperature distributions from the two solutions are given in Figure 6 for sandstone data as given Table 1. It is obvious that the steady-state solution overestimates the temperature increase at early time but the differences disappear at long times.

The transient heat conduction function $f\left(t_{D}\right)$, discussed in detail by Ramey ${ }^{[4]}$ and Willhite $^{[6]}$ is widely used for wellbore heat transfer calculations. However, it lacks a theoretical basis, except in the long-time limit of the line source equation given by Ramey. We obtain an accurate formula for $f\left(t_{D}\right)$ (see Appendix D) as a special case for a uniform and homogeneous formation (subscripts omitted):

$$
f\left(t_{D}\right)=\frac{\dot{\phi\left(1, z_{D}, t_{D}\right)}}{\omega\left[\theta\left(z_{D}, t_{D}\right)-\phi\left(1, z_{D}, t_{D}\right)\right]}
$$

It is interesting to note that in a more rigorous formulation than that of Ramey (1962), $f\left(t_{D}\right)$ is a function not only of dimensionless time $t_{D}$, but also of dimensionless depth $z_{D}$. This can be seen explicitly from Figure 7, in which $f\left(t_{D}\right)$ from Equation (35) is plotted for different dimensionless depths $z_{D}$. Only after $t_{D} \geq 500$ (2,500 hrs for this case), does $f\left(t_{D}\right)$ become independent of $z_{D}$. This means that use of an $f\left(t_{D}\right)$ independent of $z_{D}$ will not give accurate results during the early transient time for wellbore heat transfer problems, even for the homogeneous formation and the linear vertical temperature distribution. 


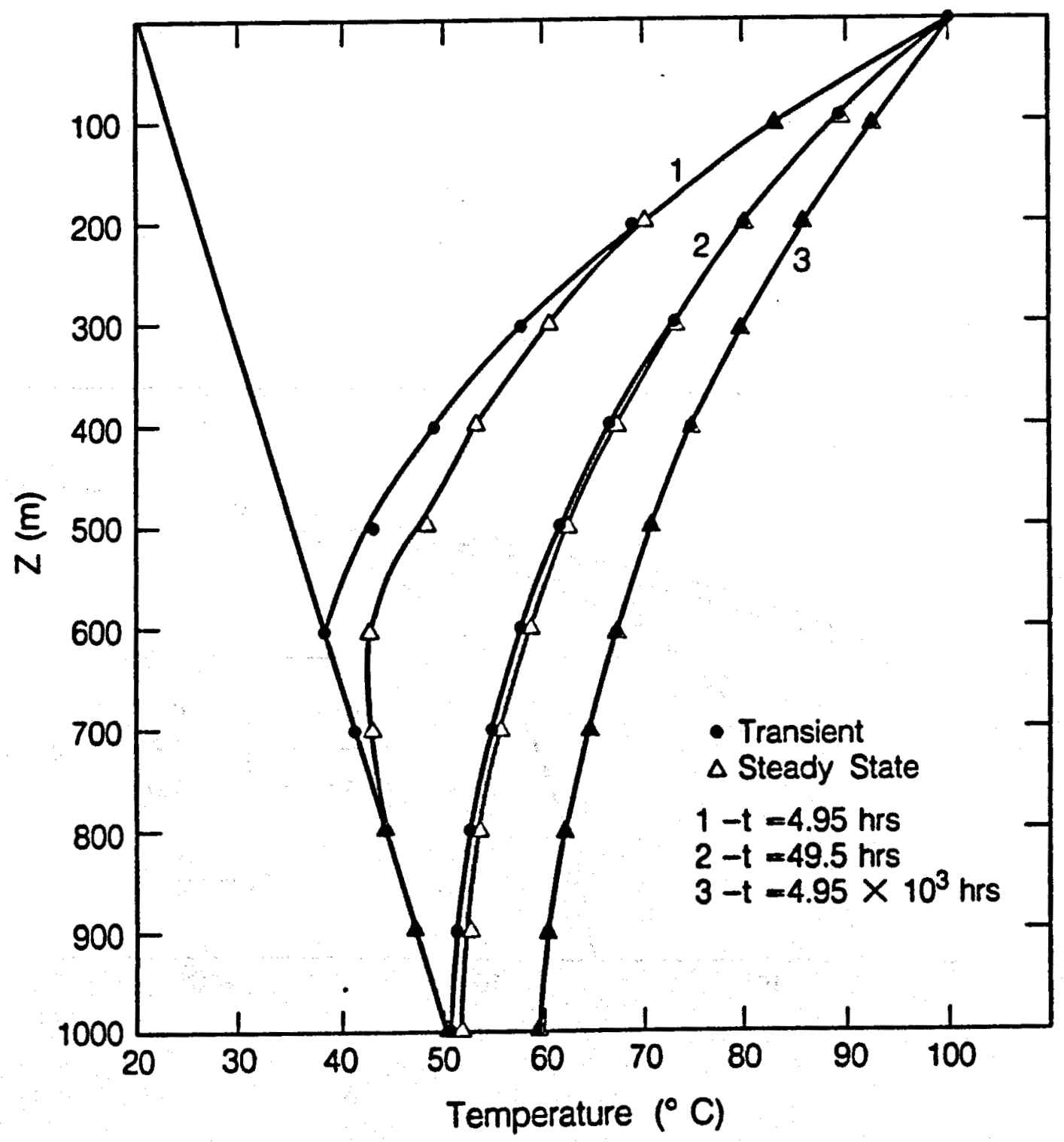

X8L $882 \cdot 10200$

Figure 6 Single-layer case: Comparison of steady-state and transient heat transfer in wellbore. 


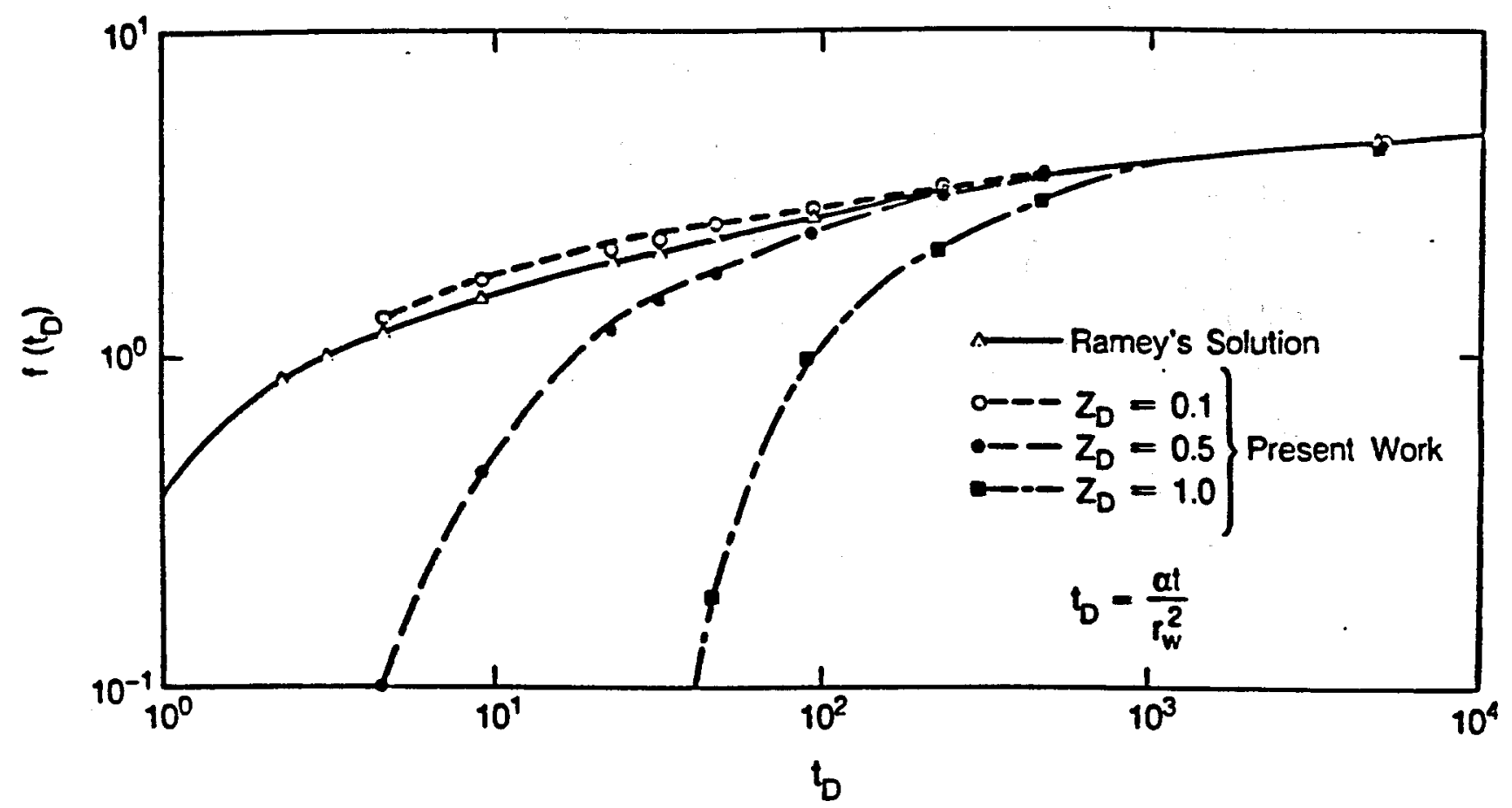

XBL $882-10049$

Figure 7 Effect of depth on $f\left(t_{D}\right)$. 


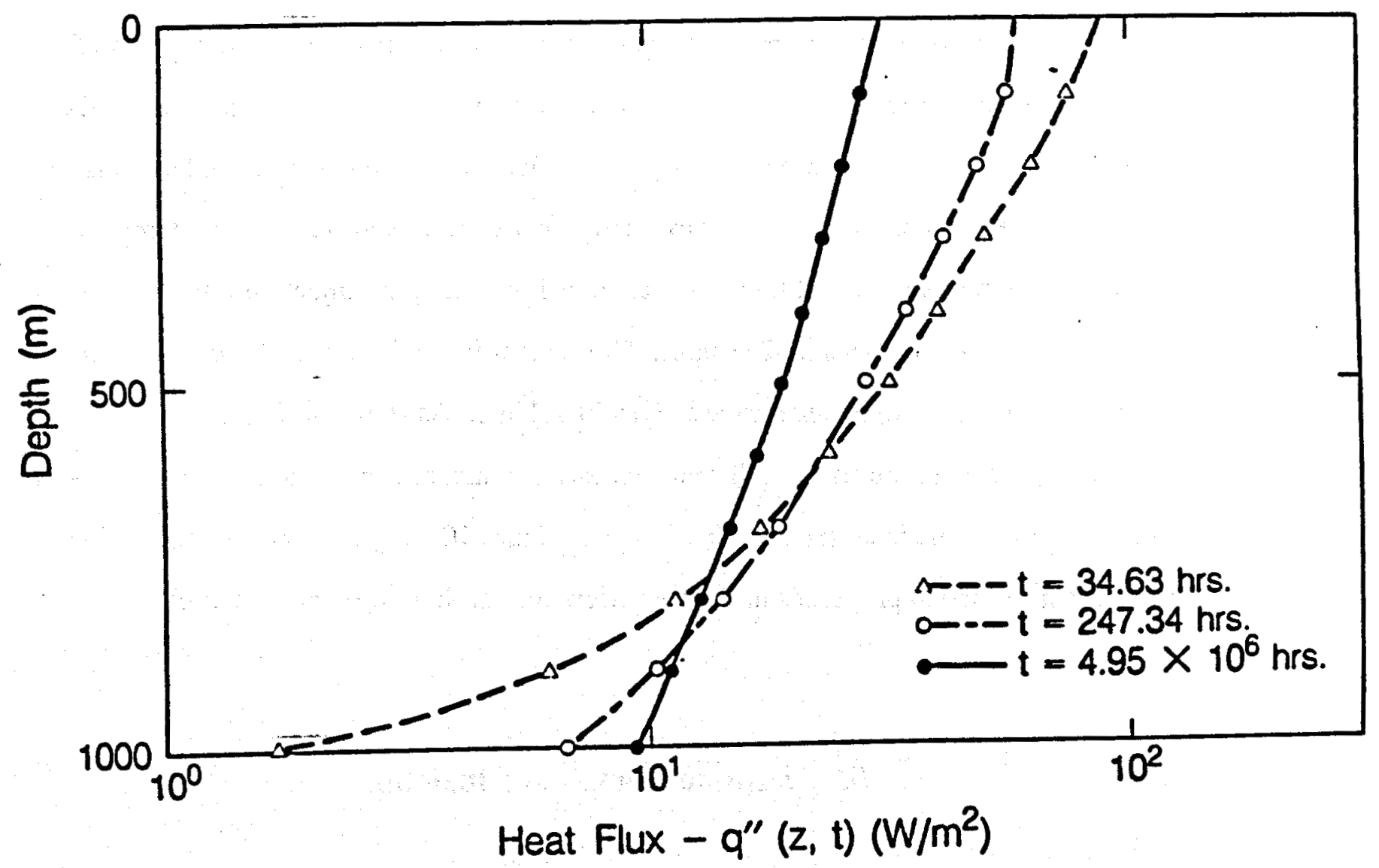

XBL 882-10201

Figure 8 Heat flux into formation. 
Heat loss (or gain) from wells is important for evaluating a thermal recovery project. The behavior of heat flux and cumulative heat transfer into the surrounding formation are given in Figures 8 and 9 for hot-water injection into a well in a homogeneous sandstone formation. The calculation parameters are in Table 1. It is obvious from Figure 9 that the heat losses from the well never reach a steady state since the formation is modeled as an infinite radial system.

In an actual reservoir, formations are neither uniform nor homogeneous, the well may penetrate a number of aquifers and aquitards with quite different thermal and physical properties, and layered formations may be a realistic approximation. In order to take into account effects of formation heterogeneity on wellbore heat transfer, the temperature distribution along the wellbore was calculated for hot-water injection into a formation consisting of two layers. The upper 500 meters is sandstone, and the lower 500 meters is clay. Problem parameters are given in Table 1. As shown in Figure 10, if only sandstone properties are used, well temperatures are inderestimated since thermal diffusivity in sandstone is larger than that in clay. Figure 10 suggests that the assumption of constant formation properties introduces errors for non-homogeneous reservoirs.

\section{Summary and Conclusions}

In summary, the following conclusions have been obtained through this work:

1. An analytical solution for wellbore heat transmission in a layered formation has been developed. It provides temperature distributions with time and depth, and radial distance both in the wellbore and in the formation, as well as the rate of heat transfer between wellbore and formation.

2. An exact solution, both in real space and in Laplace space, for Wellbore heat transmission have been obtained. The chief assumption made is that vertical 


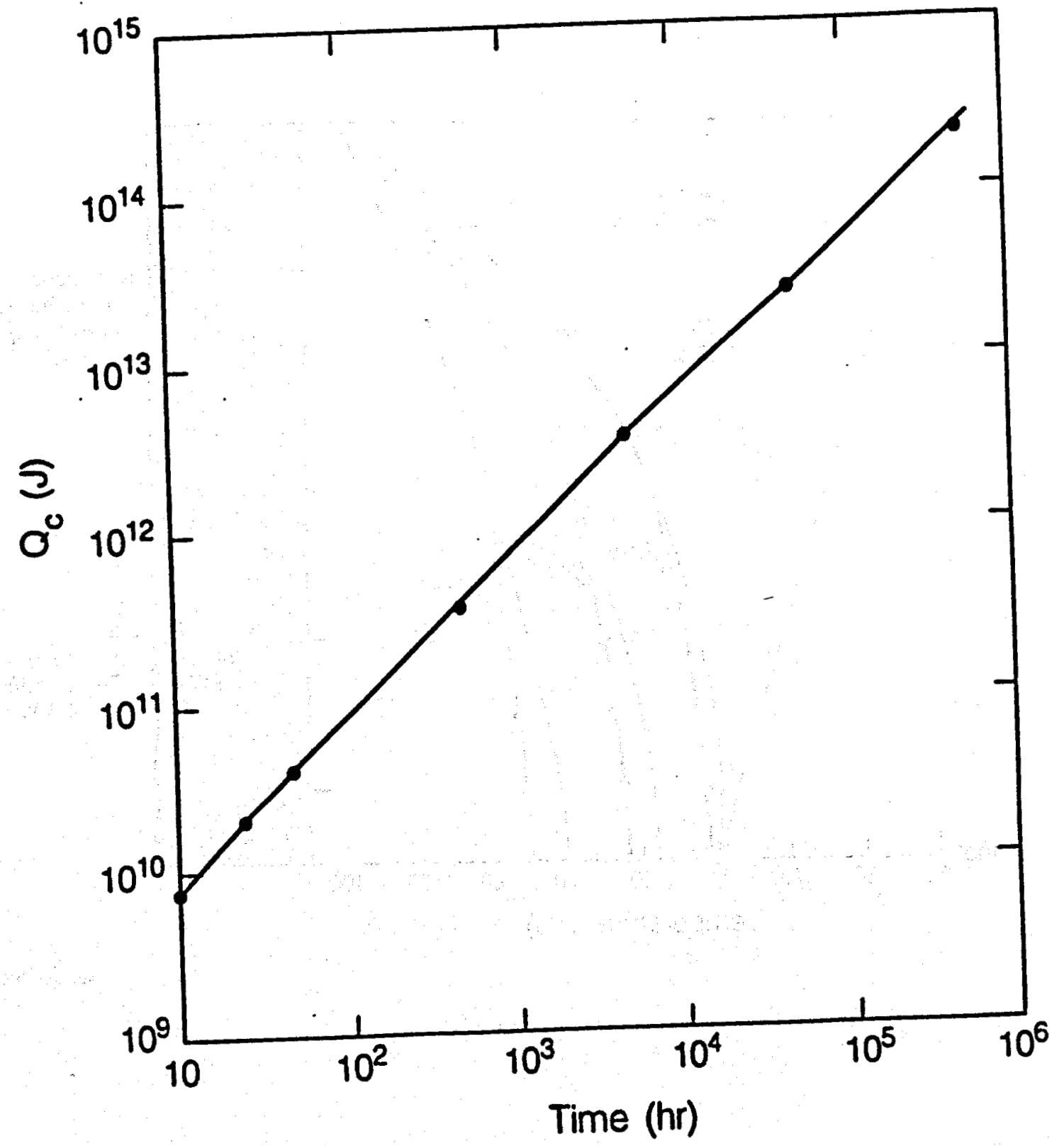

XBL 882-10099

Figure 9 Cumulative heat transfer into formation. 


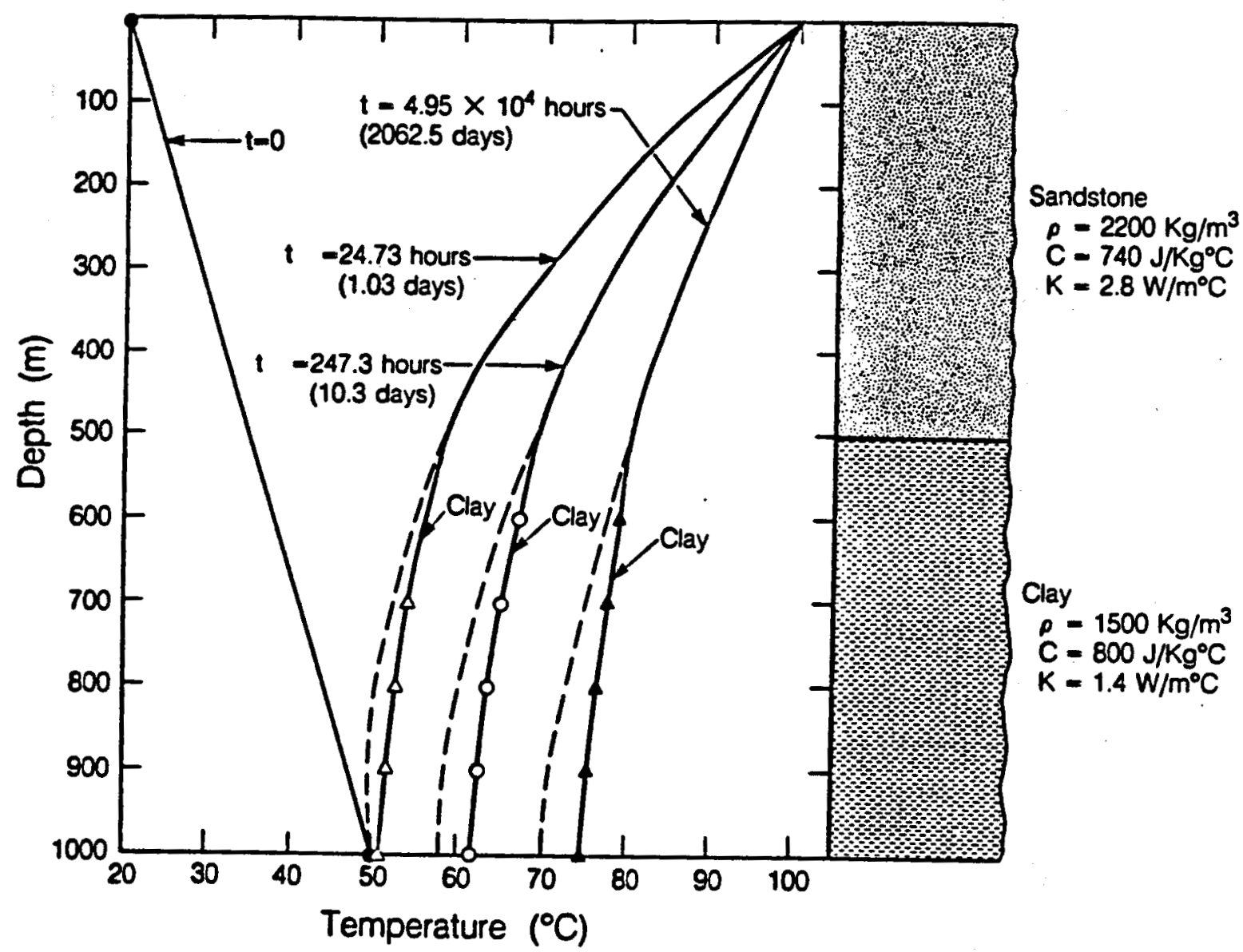

XBL 882.10051

Figure 10 Wellbore temperature distribution of sandstone-clay 2-layer formation. Dashed lines indicate profiles for a single sandstone layer temperature. 
conduction effects in the formation can be neglected. Heat transfer between wellbore fluid and the formation is treated in a fully transient fashion.

3. A more accurate formula is obtained for the widely-used transient heat conduction function $f\left(t_{D}\right)$ of thermal resistance. It has been found that $f\left(t_{D}\right)$ depends not just on time but also on depth.

4. The approximation of using a depth-independent heat conduction function $f\left(t_{D}\right)$ will give large errors for early times.

5. Vertical heat conduction in the formation may be ignored for engineering application.

6. Effects of formation heterogeneity should be included for more accurate predictions of wellbore heat transmission in non-homogeneous formations. 


\section{References}

[1] Lessem, L. B., Greytok, F., Marotta, F., and Mcketta, J. J., Jr., " A Method of Calculating the Distribution of Temperature in Flowing in Gas Wells," Trans., AIME (1957) 210, 169.

[2] Squier, D. P., Smith, D. D. and Dougherty, E. L., "Calculated Temperature Behavior of Hot-Water Injection Wells," J. Pet. Tech. (April 1962), 436-440.

[3] Moss, J. T. and White, P. D., "How to Calculate Temperature Profiles in a Water-Injection Well," Oil and Gas Jour. (March 9, 1959) 57, No. 11, 174.

[4] Ramey, H. J. Jr., "Wellbore Heat Transmission," J. Pet. Tech. (April 1962) 427-435.

[5] Satter, A., "Heat Losses During Flow of Steam Down a Wellbore," J. Pet. Tech. (July 1965) 845-851.

[6] Willhite, G. P., "Over-All Heat Transfer Coefficients in Steam and Hot Water Injection Wells," J. Pet. Tech. (May 1967) 607-615.

[7] Durrant, A. J. and Thambynayagam, R. K. M., "Wellbore Heat Transmission and Pressure Drop for Steam/Water Injection and Geothermal Production: A Simple Solution Technique," SPE Reservoir Eng. (March 1986), 148-157. 
[8] Farouq Ali, S. M., "A Comprehensive Wellbore Steam/Water Flow Model for Steam Injection and Geothermal Applications" SPEJ (October 1981) 527-534.

[9] Wooley, G. R., "Computing Downhole Temperatures in Circulation, Injection and Production Wells," J. Pet. Tech. (Sept. 1980) 1509-1522.

[10] Stehfest, H., "Numerical Inversion of Laplace Transforms," Communications, ACM (January 1970) 13, No. 1, 47-49.

[11] Numerical Algorithms Group: NAG FORTRAN Library Manual, Mark 11, Vol. 1, Chapter D01, 1984.

[12] Barelli, A. and Palama, A., "A New Method for Evaluating Formation Equilibrium Temperature in Holes During Drilling," Geothermics, (1981) 10, No. 2, 95-102.

[13] Carslaw, H. S. and Jaeger, J. C., "Conduction of Heat in Solids," Second edition, Oxford University Press, London (1959).

[14] Hildebrand, F. B., "Advanced Calculus for Applications," Second edition, Prentice-Hall, Inc., Englewood Cliffs (1976). 


\section{Appendix A.}

\section{Development of Governing Equations}

The physical system of heat transfer inside the tubing and flow in the formation should be considered as a whole system, but the governing equations for heat fiow are different in the two flow regions since heat transfer in the tubing is dominated by convection, while heat transfer is assumed by conduction only in the formation. Let us derive the flow equations separately for flow in the tubing and flow in the formation here:

\section{Flow in the tubing}

As shown in Figure A-1 and in Figure 1, by using the assumptions in Section 3, the energy conservation for the flowing fluid gives,

$$
\pi \pi_{t}^{2} d z p_{t} c_{t} \frac{\partial T_{1 j}}{\partial t}=-2 \pi \pi_{t} d z q_{j}^{\prime \prime}-\dot{m} d\left[h+\frac{V_{m}^{2}}{2}-g z\right]
$$

where the mass flow rate is,

$$
\dot{\mathrm{m}}=\pi \mathrm{r}_{\mathrm{t}}^{2} \mathrm{p}_{\mathrm{t}} \mathrm{V}_{\mathrm{m}}
$$

and the wellbore heat flux into the formation is,

$$
q_{r}^{\prime \prime}=U\left(T_{1 j}-\left.T_{2 j}\right|_{r=r w}\right)
$$

By definition, change in enthalpy is,

$$
d h=d e+d(p v)
$$

for a noncompressible liquid, (A-4) becomes,

$$
\mathrm{dh}=\mathrm{c}_{\mathrm{r}} \mathrm{dT} \mathrm{T}_{1 \mathrm{j}}+\mathrm{vdp}
$$




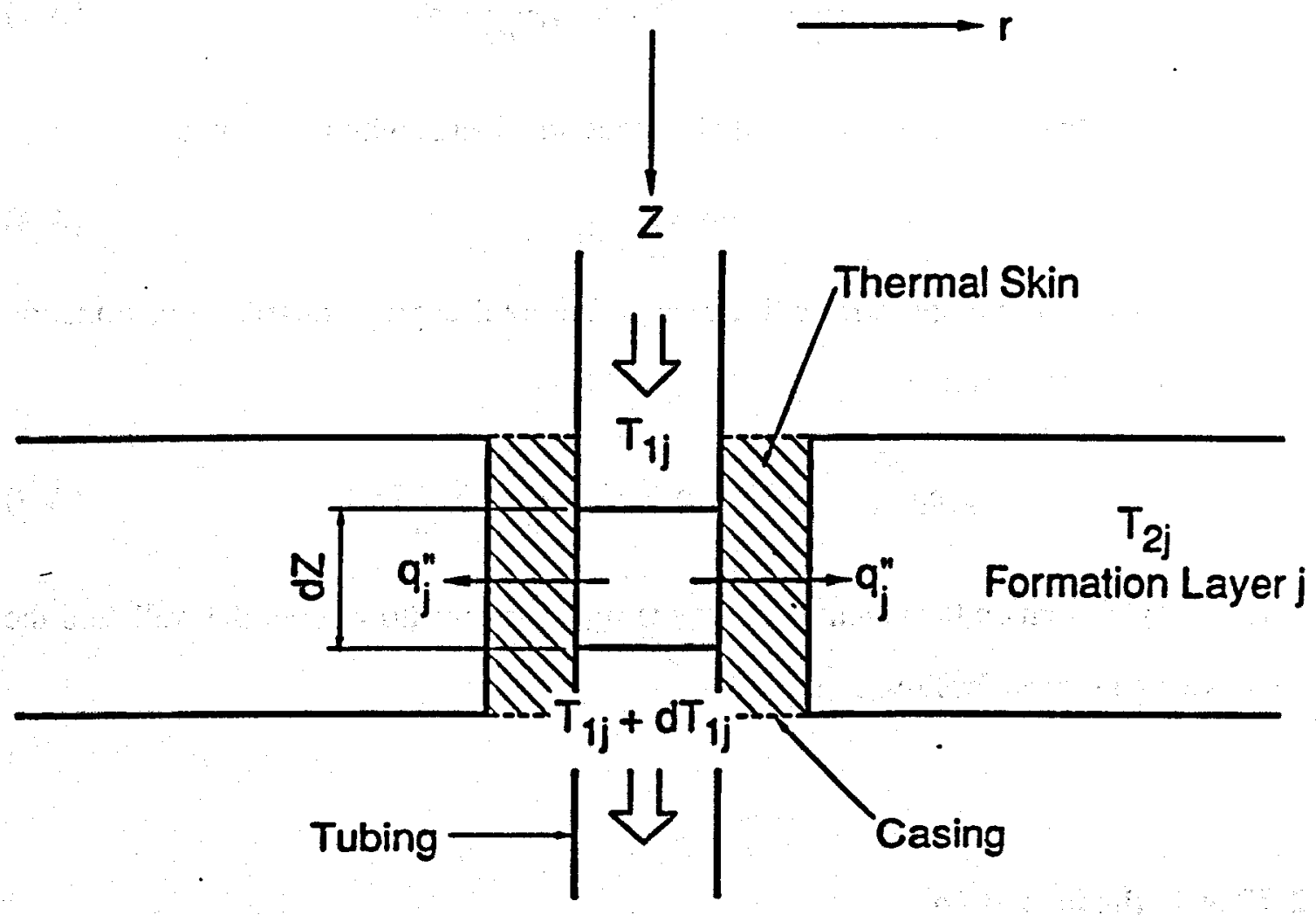

XBL 886-10261

Figure A-1 Schematic of wellbore heat transfer 
Neglecting the flowing friction, the vdp term is equal to the change in fluid head, therefore,

$$
\mathrm{dh}=\mathrm{c}_{\mathrm{c}} \mathrm{dT} \mathrm{T}_{1 \mathrm{j}}+\mathrm{gdz}
$$

Introducing (A-2) and (A-6) into (A-1), and noting that the fluid flow rate in the well is constant, we have, for liquid flow:

$$
\rho_{t} c_{t} \frac{\partial T_{1 j}}{\partial t}+\frac{2}{r_{t}} q_{j}^{\prime \prime}+\rho_{t} c_{t} V_{m} \frac{\partial T_{1 j}}{\partial z}=0
$$

If the flowing fluid is a perfect gas, enthalpy does not change with pressure, so

$$
\mathrm{dh}=\mathrm{c}_{\mathrm{t}} \mathrm{dT} \mathrm{T}_{1 \mathrm{j}}
$$

Thus, the potential energy term will appear in the total energy conservation, Equation (A-1) becomes, for gas fiow,

$$
\rho_{t} c_{t} \frac{\partial T_{1 j}}{\partial t}+\frac{2}{r_{t}} q_{r}^{\prime \prime}+\rho_{t} c_{t} V_{m}\left[\frac{\partial T_{1 j}}{\partial z} \pm \frac{g}{c_{t}}\right]=0
$$

where the plus sign on the potential energy term is used for flow down the wall, and the negative sign is used for flow up the wall.

\section{Flow in the formation}

If the vertical heat conduction in the formation is neglected, in comparison with horizontal flow, and the only heat transfer mode in the formation is by conduction, the flow of heat in the formation layer is described by the following radial transient-heat conduction equation,

$$
\frac{1}{r} \frac{\partial}{\partial r}\left(\mathrm{rK}_{\mathrm{j}} \frac{\partial \mathrm{T}_{2 \mathrm{j}}}{\partial \mathrm{r}}\right)=\rho_{\mathrm{j}} \mathrm{c}_{\mathrm{j}} \frac{\partial \mathrm{T}_{2 \mathrm{j}}}{\partial t}
$$

The initial and boundary conditions are as follows: 
1. The initial temperature of the surrounding earth and the wellbore is an arbitrary function of depth alone, the temperature distribution functions for each layer can be different, but continuous at the interfaces.

2. The surface temperature is a constant.

3. The injection or production temperature is constant.

4. The heat flow by convection crosses the wellbore thermal skin into the formation by Fourier's law of heat conduction.

5. The formation is a radially infinite system, the temperature at the outer or infinite boundary is not affected by the temperature disturbance at the wellbore.

These conditions are written mathematically in Section 2. 


\section{Appendix B.}

\section{Analytical Solution in Laplace Space}

In terms of the dimensionless variables defined in Eq. (11) - (15), the problem becomes

$$
\begin{gathered}
\frac{\partial \theta_{j}}{\partial t_{D}}+\frac{\partial \theta_{j}}{\partial z_{D}}+\beta_{j}\left(\theta_{j}-\left.\phi_{j}\right|_{z_{D}=1}\right)+\delta_{j}\left(z_{D}\right)=0 \\
\frac{\partial^{2} \phi_{j}}{\partial x_{D}^{2}}+\frac{1}{T_{D}} \frac{\partial \phi_{j}}{\partial t_{D}}=\sigma_{j} \frac{\partial \phi_{j}}{\partial t_{D}}
\end{gathered}
$$

where $j=1,2, \ldots N$; and

$$
\begin{aligned}
& \beta_{j}=\frac{2 U_{j} H}{p_{t} c_{t} r_{t} V_{m}} \\
& \delta_{j}\left(z_{D}\right)=\left\{\begin{array}{lr}
\xi_{j}\left(z_{D}\right) & \text { for liquid flow } \\
\xi_{j}\left(z_{D}\right) \pm \frac{H g}{\left(T_{\text {inj }}-T_{2 i r}\right) c_{t}} & \text { for gas flow }
\end{array}\right. \\
& \xi_{j}\left(z_{D}\right)=\frac{H_{j}(z)}{T_{i n j}-T_{a i r}} \\
& \sigma_{j}=\frac{\rho_{j} c_{j} V_{m} r_{w}^{2}}{H K_{j}}
\end{aligned}
$$

with initial conditions:

$$
\begin{gathered}
\theta_{j}\left(z_{D}, t_{D}=0\right)=0 \\
\phi_{j}\left(I_{D}, z_{D}, t_{D}=0\right)=0
\end{gathered}
$$

and boundary conditions:

$$
\begin{gathered}
\theta_{1}\left(z_{D}=0, t_{D}\right)=1 \\
\theta_{j}\left(z_{D j-1}, t_{D}\right)=\theta_{j-1}\left(z_{D j-1}, t_{D}\right)
\end{gathered}
$$




$$
\begin{gathered}
(j=2,3, \ldots N) \\
\left.\frac{\partial \phi_{j}}{\partial r_{D}}\right|_{T_{D}=1}=\omega_{j}\left[\left.\phi_{j}\right|_{I_{D}=1}-\theta_{j}\right] \\
\lim _{I_{D} \rightarrow \infty} \phi_{j}\left(r_{D}, z_{D}, t_{D}\right)=0
\end{gathered}
$$

In (B-11)

$$
\omega_{j}=\frac{U_{j} r_{t}}{K_{j}}
$$

The Laplace transforms of $\theta_{j}\left(z_{D}, t_{D}\right)$ and $\phi_{j}\left(r_{D}, z_{D}, t_{D}\right)$ are defined as follows: ${ }^{[13]}$

$$
\begin{gathered}
\bar{\theta}_{j}\left(z_{D}, s\right)=\int_{0}^{\infty} \theta\left(z_{D}, t_{D}\right) e^{-t_{D S}} d t_{D} \\
(j=1,2, \ldots N)
\end{gathered}
$$

and

$$
\begin{gathered}
\bar{\phi}_{j}\left(r_{d,} z_{D}, s\right)=\int_{0}^{\infty} \phi_{j}\left(r_{D}, z_{D}, t_{D}\right) e^{-b_{D} s} d t_{D} \\
(j=1,2, \ldots N)
\end{gathered}
$$

Application of the Laplace transformation to the partial differential equations (B1), (B-2) and the boundary conditions (B-9) - (B-12) with incorporating the initial conditions (B-7), (B-8) yields

$$
\begin{gathered}
\frac{d \bar{\theta}_{j}}{d z_{D}}+\left(s+\beta_{j}\right) \bar{\theta}_{j}-\left.\beta_{j} \bar{\phi}_{j}\right|_{s_{D}=1}+\frac{\delta_{j}\left(z_{D}\right)}{s}=0 \\
\frac{d^{2} \bar{\phi}_{j}}{d r_{D}^{2}}+\frac{1}{I_{D}} \frac{d \bar{\phi}_{j}}{d r_{D}}-\sigma_{j} s \bar{\phi}_{j}=0 \\
\left.\frac{d \bar{\phi}_{j}}{d r_{D}}\right|_{s_{D}=1}=\omega_{j}\left[\left.\bar{\phi}_{j}\right|_{r_{D}=1}-\bar{\theta}_{j}\right]
\end{gathered}
$$




$$
\begin{gathered}
\bar{\theta}_{1}\left(z_{D}=0, s\right)=\frac{1}{s} \\
\bar{\theta}_{j}\left(z_{D j-1}, s\right)=\bar{\theta}_{j-1}\left(z_{D j-1}, s\right)
\end{gathered}
$$

where $j=1,2, \ldots N$. The solutions of (B-16), (B-17) in Laplace space, satisfying the boundary condition (B-18) - (B-20), are:

$$
\begin{gathered}
\bar{\theta}_{j}\left(z_{D}, s\right)=C_{j}(s) \exp \left\{-\left[s+\beta_{j}-D_{j}(s)\right] z_{D}\right\}+Y_{j}\left(z_{D}, s\right) \\
\bar{\phi}_{j}\left(I_{D}, z_{D}, s\right)=\frac{\omega_{j} \bar{\theta}_{j}\left(z_{D}, s\right) K_{o}\left(\sqrt{\sigma_{j} s} I_{D}\right)}{\omega_{j} K_{o}\left(\sqrt{\sigma_{j} s}\right)+\sqrt{\sigma_{j} s} K_{1}\left(\sqrt{\sigma_{j} s}\right)}
\end{gathered}
$$

where $Y_{j}\left(z_{D}, s\right)$ are the particular solutions of (B-16), which depend on the initial temperature profile.

$$
\begin{gathered}
C_{1}=\frac{1}{s}-Y_{1}\left(z_{D}=0, s\right) \\
C_{j}=\left[\bar{\theta}_{j-1}\left(z_{D j-1}, s\right)-Y_{j}\left(z_{D j-1}, s\right)\right] \exp \left\{\left[s+\beta_{j}-D_{j}(s)\right] z_{D j-1}\right\} \\
(j=2,3, \ldots N)
\end{gathered}
$$

and

$$
D_{j}(s)=\frac{\beta_{j} \omega_{j} K_{o}\left(\sqrt{\sigma_{j} s}\right)}{\omega_{j} K_{o}\left(\sqrt{\sigma_{j} s}\right)+\sqrt{\sigma_{j} s} K_{1}\left(\sqrt{\sigma_{j} s}\right)}
$$

Heat flow rate into (or from) the formation in layer $j$ is

$$
2 \pi r_{1} q_{j}^{\prime \prime}(z, t)=-\left.2 \pi r_{w} K_{j} \frac{\partial T_{2 j}}{\partial t}\right|_{r=r_{w}} \doteq 2 \pi r_{t} U_{j}\left[T_{1 j}-\left.T_{2 j}\right|_{r=s_{w}}\right]
$$

so that, the heat flux at the tubing surface $\left(r=r_{1}\right)$,

$$
\begin{aligned}
q_{j}^{\prime \prime}(z, t) & =\left.\frac{-K_{j}\left(T_{i n j}-T_{i i z}\right)}{r_{t}} \frac{\partial \phi_{j}}{\partial x_{D}}\right|_{s_{D}=1} \\
& =-U_{j}\left(T_{i n j}-T_{z i r}\right)\left[\phi_{j}\left(1, z_{D}, t_{D}\right)-\theta_{j}\left(z_{D}, t_{D}\right)\right]
\end{aligned}
$$


$-35-$

Total heat flux into the formation is defined as:

$$
Q_{t}(t)=\sum_{j=1}^{N} \int_{\psi_{1-1}}^{z_{1}} 2 \pi_{t} q_{j}^{\prime \prime}(z, t) d z
$$

and total cumulative heat transfer is defined as:

$$
Q_{c}(t)=\int_{0}^{t} Q_{r}(\tau) d \tau
$$

For linear vertical initial temperature distributions in each layer of the formation, we can obtain the explicit form of the particular solution $Y_{j}\left(z_{D}, s\right)$ as:

$$
Y_{j}\left(z_{D}, s\right)=-\frac{\delta_{j}}{s\left[s+\beta_{j}-D_{j}(s)\right]}
$$

then the expressions for the total heat flux in the Laplace space can be derived as follows:

$$
\begin{gathered}
\bar{Q}_{l}(s)=2 \pi r_{t} H\left(T_{i n j}-T_{i j}\right) \sum_{j=1}^{N} U_{j}\left(1-\frac{D_{j}(s)}{\beta_{j}}\right) \\
\cdot\left\{[ \overline { \theta } _ { j - 1 } ( z _ { D j - 1 } , s ) + \frac { \delta _ { j } } { s [ s + \beta _ { j } - D _ { j } ( s ) ] } ] \left[1-\exp \left(-\left(s+\beta_{j}-D_{j}(s)\right)\left(z_{D_{j}}-z_{D_{j}-1}\right)\right]\right.\right. \\
\left./\left(s+\beta_{j}-D_{j}(s)\right)-\frac{\delta_{j}}{s\left(s+\beta_{j}-D_{j}(s)\right)}\left(z_{D_{j}}-z_{D j-1}\right)\right\}
\end{gathered}
$$

and the total cumulative heat flow rate is

$$
\begin{aligned}
\bar{Q}_{c}(s) & =L^{-1}\left\{\frac{H}{V_{m}} \int_{0}^{b} Q_{r}(\tau) d \tau\right\} \\
& =\frac{H \bar{Q}_{c}(s)}{s V_{m}}
\end{aligned}
$$




\section{Appendix C.}

\section{Analytical Solutions in Real Space}

For the case of linear initial temperature distributions in each layer of the formation, Equation B-21 can be written as:

$$
\begin{aligned}
\bar{\theta}_{j}\left(z_{D}, s\right) & =\bar{A}_{j}(s)+\left[\bar{\theta}_{j-1}\left(z_{D_{j-1}}, s\right)-\bar{A}_{j}(s)\right] \bar{B}_{j}\left(z_{D}, s\right) \\
(j & =1,2, \ldots N)\left(z_{D j-1}, \leq z_{D} \leq z_{D j}\right)
\end{aligned}
$$

where

$$
\begin{gathered}
\bar{A}_{j}(s)=-\frac{\delta_{j}}{s\left(s+\beta_{j}-D_{j}(s)\right)}=\frac{1}{s} \bar{f}_{j}(s)\left(\bar{f}_{j}(s)=s \bar{A}_{j}(s)\right) \\
\bar{B}_{j}\left(z_{D}, s\right)=\exp \left[-\beta_{j}\left(z_{D}-z_{D j-1}\right)\right] \exp \left[-s\left(z_{D}-z_{D j-1}\right)\right] \\
\exp \left[D_{j}(s)\left(z_{D}-z_{D j-1}\right)\right]
\end{gathered}
$$

and

$$
\bar{\theta}_{0}\left(z_{D O}, s\right)=\frac{1}{s}
$$

the dimensionless temperature function in the formation,

$$
\begin{gathered}
\bar{\phi}_{j}\left(r_{D}, z_{D}, t_{D}\right)=\bar{\theta}_{j}\left(z_{D}, s\right) \bar{g}_{j}\left(r_{D}, s\right) \\
(j=1,2, \ldots N)
\end{gathered}
$$

where

$$
\bar{g}_{j}\left(I_{D}, s\right)=\frac{\omega_{j} K_{o}\left(\sqrt{\sigma_{j} s} r_{D}\right)}{\omega_{j} K_{o}\left(\sqrt{\sigma_{j} s}\right)+\sqrt{\sigma_{j} s} K_{1}\left(\sqrt{\sigma_{j} s}\right)}
$$

Since the functions $\bar{A}_{j}(s), \bar{B}_{j}\left(z_{D}, s\right)$ and $\bar{g}_{j}\left(r_{D}, s\right)$ all have a single branch point at the origin, we have to use the inversion theorem for Laplace transformations by evaluating 


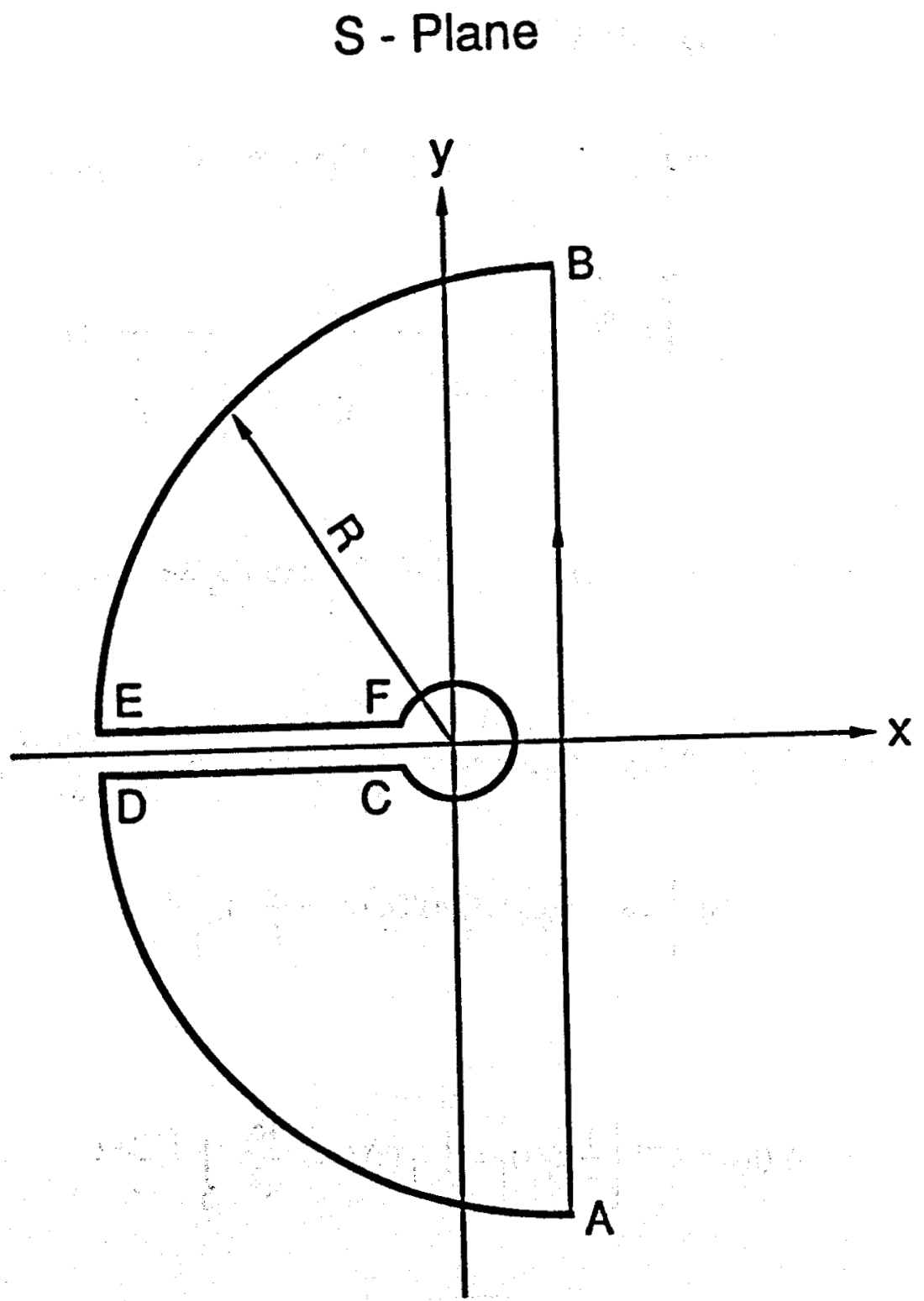

XBL 886-10260

Figure C-1 Contour for evaluating Laplace transform 
$-38-$

the contour integrals ${ }^{[13]}$. The closed contour used to inverse Laplace transform of $\bar{f}_{j}(s), \bar{B}_{j}\left(z_{D}, s\right)$ and $\bar{g} ;\left(r_{D}, s\right)$ is given in Figure $C-1$. The following inversions can be proven after some algebraic operations ${ }^{[14]}$.

$$
\begin{gathered}
f_{j}\left(t_{D}\right)=L^{-1}\left[\bar{f}_{j}(s)\right]=\frac{\delta_{j}}{2 \pi i} \int_{0}^{\infty} e^{-t_{D} \lambda}\left[\bar{f}_{j}\left(\lambda e^{-i \pi}\right)-\bar{f}_{j}\left(\lambda e^{i \pi}\right)\right] d \lambda \\
=-\frac{4 \delta_{j}}{\pi^{2} \sigma_{j}} \int_{0}^{\infty} e^{-\frac{u^{2}}{\sigma_{j}} t_{D}} \frac{u D_{j}^{*}(u)}{\left.D^{*}(u)\left[\beta_{j}-\frac{u^{2}}{\sigma_{j}}\right] R_{j}(u)\right]^{2}+\frac{4}{\pi^{2}}} d u \\
L^{-1}\left\{\exp \left[D_{j}(s)\left(z_{D}-z_{D j-1}\right)\right]=\frac{1}{2 \pi i} \int_{0}^{\infty} e^{-t_{D} \lambda}\left\{\exp \left[D_{j}\left(\lambda e^{-i \pi}\right)\left(z_{D}-z_{D j-1}\right)\right]\right.\right. \\
\left.-\exp \left[D_{j}\left(\lambda e^{i \pi}\right)\left(z_{D}-z_{D j-1}\right)\right]\right\} d \lambda=\frac{2}{\lambda \sigma_{j}} \int_{0}^{\infty} u \sin \left[\frac{2\left(z_{D}-z_{D j-1}\right)}{\pi D_{j}^{*}(u)}\right] \\
\exp \left[\left(z_{D}-z_{D j-1}\right) R_{j}(u) / D_{j}^{*}(u)-\frac{u^{2}}{\sigma_{j}} t_{D}\right] d u
\end{gathered}
$$

then

$$
\begin{gathered}
A_{j}\left(t_{D}\right)=L^{-1}\left\{\frac{1}{s} \bar{f}_{j}(s)\right\}=\int_{0}^{D} f_{j}(\tau) d \tau=\frac{4 \delta_{j}}{\pi^{2}} \cdot \int_{0}^{\infty} \frac{D^{*}(u)}{u} \\
{\left[D_{j}^{*}(u)\left[\beta_{j}-\frac{u^{\frac{u^{2}}{\sigma_{j}}} t_{D}}{\sigma_{j}}-1\right]-R_{j}(u)\right]^{2}+\frac{4}{\pi^{2}}} \\
B_{j}\left(z_{D}, t_{D}\right)=L^{-1}\left\{\bar{B}_{j}\left(z_{D}, s\right)\right\}=\exp \left[-\beta_{j}\left(z_{D}-z_{D j-1}\right)\right] L^{-1}\left\{\exp \left[-s\left(z_{D}-z_{D j-1}\right)\right]\right. \\
\left.\cdot \exp \left[D_{j},(s)\left(z_{D}-z_{D j-1}\right)\right]\right\}
\end{gathered}
$$




$$
\begin{gathered}
=\left\{\begin{array}{c}
0 \quad\left(t_{D} \leq z_{D}-z_{D j-1}\right) \\
\frac{2}{\pi \sigma_{j}} \exp \left[-\beta_{j}\left(z_{D}-z_{D j-1}\right)\right] \int_{0}^{\infty} u \sin \left[\frac{2\left(z_{D}-z_{D j-1}\right)}{\pi D_{j}^{*}(u)}\right]
\end{array}\right. \\
\cdot \exp \left[\left(z_{D}-z_{D j-1}\right) R_{j}(u) / D_{j}^{*}(u)-\frac{u^{2}}{\sigma_{j}}\left(t_{D}-z_{D}+z_{D j-1}\right)\right] d u \\
\left(t_{D}>z_{D}-z_{D j-1}\right)
\end{gathered}
$$

Taking the inverse Laplace transform of (C-1) and using (C-9), (C-10) and the convolution property of the Laplace transform, we have

$$
\begin{gathered}
\theta_{j}\left(z_{D}, t_{D}\right)=L^{-1}\left\{\bar{\theta}_{j}\left(z_{D}, s\right)\right\} \\
=A_{j}\left(t_{D}\right)+\int_{0}^{0}\left[\theta_{j-1}\left(z_{D j-1}, \tau\right)-A_{j}(\tau)\right] B_{j}\left(z_{D}, t_{D}-\tau\right) d \tau
\end{gathered}
$$

and

$$
\begin{aligned}
g_{i}\left(I_{D}, t_{D}\right)=L^{-1}\left\{\bar{g}_{j}\left(r_{D}, s\right)\right\} & =\frac{1}{2 \pi i} \int_{0}^{\infty} e^{-t_{D} \lambda}\left[\bar{g}_{j}\left(r_{D}, \lambda e^{-i \pi}\right)-\bar{g}_{j}\left(r_{D}, \lambda e^{i \pi}\right)\right] d \lambda \\
& =\frac{2}{\pi \sigma_{j} \beta_{j}} \int_{0}^{\infty} \frac{u e^{-\frac{u^{2}}{\sigma_{j}} t_{D}}}{D^{*}(u)} \\
& \left\{\left\{Y_{0}\left(u r_{D}\right)\left[\omega_{j} J_{0}(u)+w_{1}(u)\right]-J_{0}\left(u r_{D}\right)\left[u Y_{1}(u)+\omega_{j} Y_{0}(u)\right]\right\} d u\right.
\end{aligned}
$$

Then,

$$
\phi_{j}\left(r_{D}, z_{D}, t_{D}\right)=\int_{0}^{t_{D}} \theta_{j}\left(z_{D}, \tau\right) g_{j}\left(r_{D}, t_{D}-\tau\right) d \tau
$$

In the above solutions 


$$
\begin{aligned}
& R_{j}(u)=J_{0}(u)\left[\omega_{j} J_{0}(u)+u J_{1}(u)\right]+Y_{0}(u)\left[\omega_{j} Y_{0}(u)+u Y_{1}(u)\right] \\
& D_{j}^{*}(u)=\left\{\left[\omega_{j} Y_{0}(u)+u Y_{1}(u)\right]^{2}+\left[\omega_{j} J_{0}(u)+u J_{1}(u)\right]^{2}\right\} / \beta_{j} \omega_{j}
\end{aligned}
$$

For layer 1; the solution (C-11) is simplified as Eq. (26). 


\section{Appendix D. \\ Heat Conduction Function of Thermal Resistance}

For the special case of a formation that is homogeneous and isotropic, i.e., one layer formation, the heat conduction function of thermal resistance is derived as follows. The assumption of steady-state wellbore heat transfer, and the energy balance between the wellbore and the formation give (subscripts omitted):

$$
2 \pi r_{t} q^{\prime \prime}=\frac{2 \pi K\left[\left.T_{2}\right|_{r=r_{x}}-G(z)\right]}{f(t)}
$$

then the heat conduction function $f(t)$ is,

$$
f(t)=\frac{K}{T_{t}}\left[\left.T_{2}\right|_{t=T_{w}}-G(z)\right] / q^{\prime}
$$

Introducing (B-27) into equation (D-2), we obtain in terms of the dimensionless variables,

$$
f\left(t_{D}\right)=\frac{\Phi\left(1, z_{D}, t_{D}\right)}{\omega\left[\theta\left(z_{D}, t_{D}\right)-\Phi\left(z_{D}, t_{D}\right)\right]}
$$

where, $\omega=\frac{U r_{t}}{K}$ 
Appendix E.

Fortran Program for Calculation of Analytical Solutions

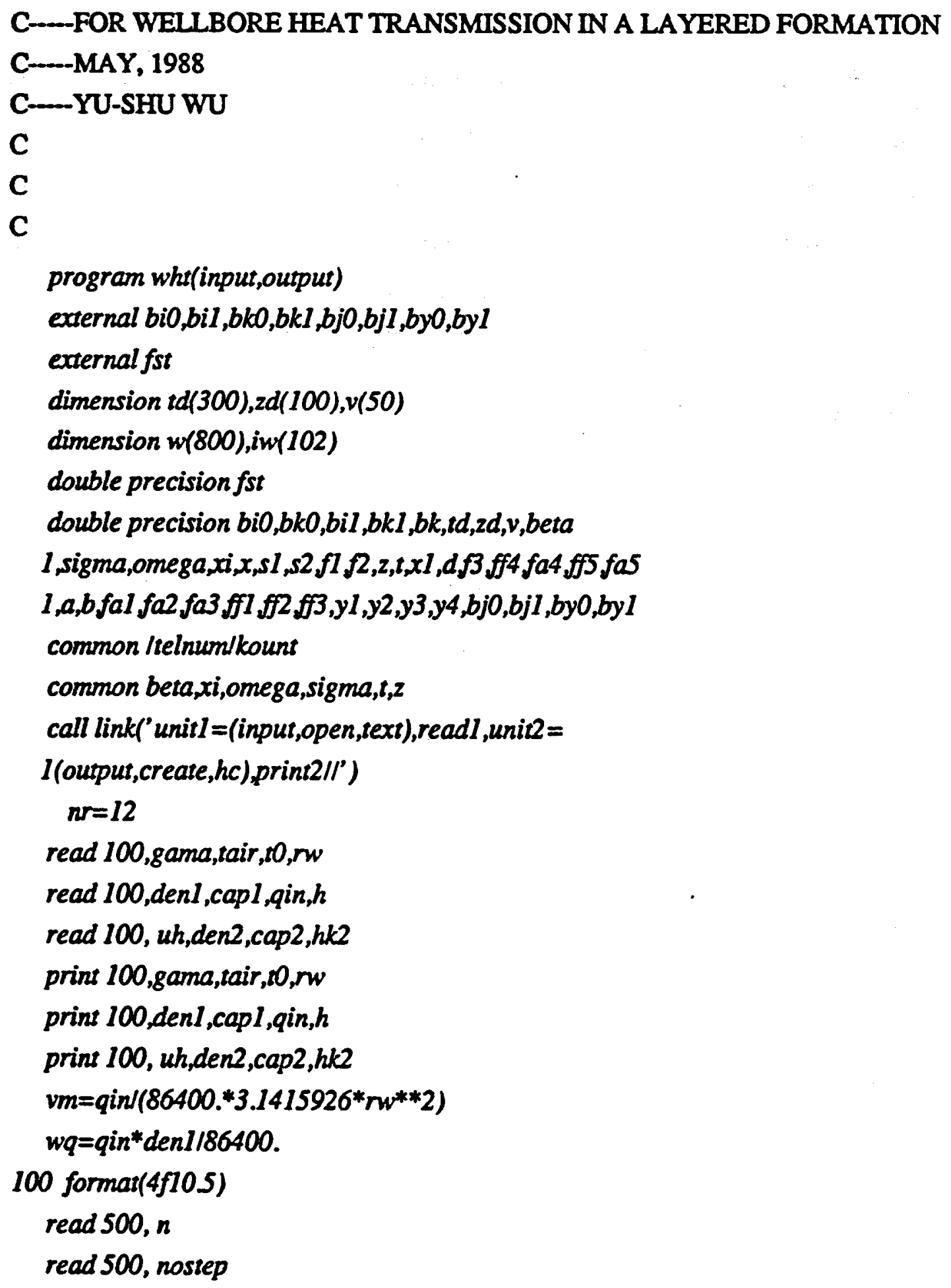




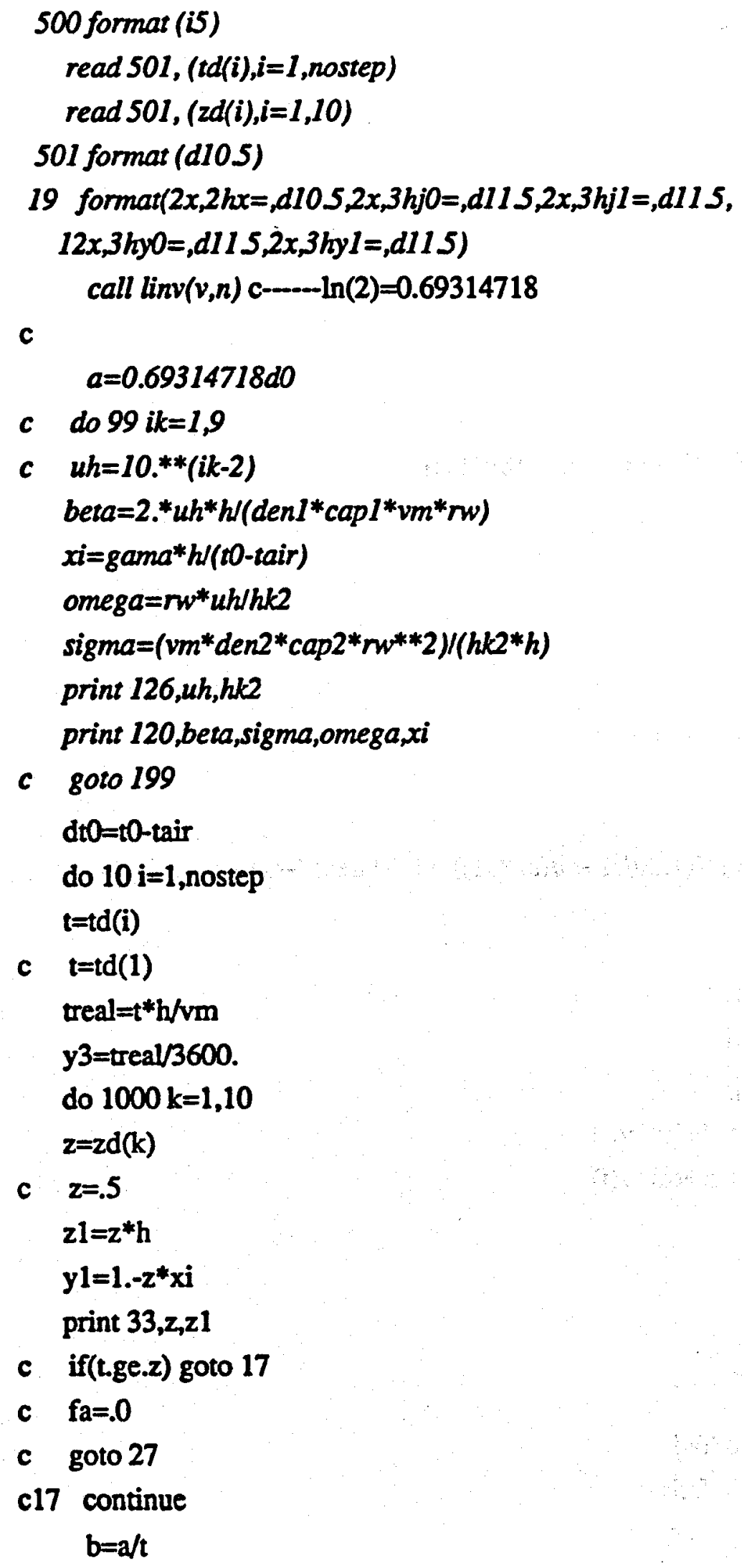

c evaluate function in Laplace space by substituting $i^{*} \ln (2) / t$ for $S$ 
c

$$
\begin{aligned}
& f a 1=0 . d 0 \\
& f a 2=0 . d 0 \\
& f a 3=0 . d 0 \\
& f a 4=0 . d 0 \\
& f a 5=0 . d 0 \\
& \text { do } 20 j=1, n \\
& s=j * b \\
& x=d s q r t(\text { sigma*s) }
\end{aligned}
$$$$
\text { bk }=b k O(x)
$$$$
\mathrm{d}=\text { omega*beta*bl/(omega*bk+x*bk1(x)) }
$$$$
s 1=s+\text { beta }-d
$$$$
\text { s2 }=\text { beta-d }
$$$$
\mathrm{f} 1=\mathrm{dexp}(-\mathrm{s} 1 * \mathrm{z})
$$$$
\mathrm{f} 2=\operatorname{dexp}(-\mathrm{s} 2 * \mathrm{z})
$$$$
\text { ff1 }=x i^{*}(\mathrm{f1}-1 .) /\left(s^{*} s 1\right)+\mathrm{f} 1 / \mathrm{s}
$$$$
\text { ff } 2=x i *(f 2-1 .) /(s * s 2)+f 2 / s
$$$$
\mathrm{ff3}=\mathrm{d} * \mathrm{ff} 1 / \text { beta }
$$$$
\text { if(k.eq.10) then }
$$$$
\text { ff4 }=(1 . d 0-d / b e t a) *((1 . d 0 / s 1+x i /(s 1 * s 1)) *(1 . d 0-d \exp (-s 1))-x i / s 1) / s
$$$$
\text { ff5 }=\mathrm{ff} 4 / \mathrm{s}
$$

endif

$\mathrm{fal}=\mathrm{fa} 1+\mathrm{ff} 1 * \mathrm{v}(\mathrm{j})$

$\mathrm{fa} 2=\mathrm{fa} 2+\mathrm{ff} 2 * v(j)$

$\mathrm{fa} 3=\mathrm{fa} 3+\mathrm{ff} 3 * v(j)$

if(k.eq.10) fa4=fa4+ff4*v(j)

if(k.eq.10) fas $=f a 5+f f 5^{*} v(j)$

20 continue

27 continue

$f a 1=b * f a 1$

fa2 $=b * f a 2$

fa3 $=b * f a 3$

if(k.eq. 10) fa $4=b * f a 4$

if(k.eq.10) fas=b*fas

$f t=f a 3 /($ omega* $(f a 2-f a 3)$ )

c 
c

c----fal=dimensionless wellbore temperature for steady heat

flow in tubing

c---fa2=dimensionless wellbore temperature for transient heat

flow in tubing

c-m-fa2=dimensionless formation temperature at the wellbore $(r=r w)$

c----fa4=dimensionless total flux of heat into formation

c-- fa5=dimensionless total cumulative rate into formation

$\mathrm{c}$-- $\mathrm{ft}=$ heat conduction function defined in this work

c---ftr=heat conduction function of Ramey's

c

c

$t a y=t a i r+g a m a * z 1$

$t r l=f a l * d+0+t a y$

$t r 2=f a 2 * d t 0+\infty x y$

$t r 3=f a 3 * d t 0+t a y$

$a a l=w q^{*} \operatorname{capl} l^{*}\left(h k 2+n w^{*} u h^{*} f t\right) /\left(2 . * 3.1415926^{*} r w^{*} u h^{*} h k 2\right)$

alphal $=h k 2 / d e n 2 /$ cap2

$t d r=a l p h a I * t r e a l l\left(r w^{*} r w\right)$

$f t r=-\operatorname{alog}(1 . /(2 . * s q r t(t d r)))-290$

$a a 2=w q^{*} \operatorname{capl} 1^{*}\left(h k 2+r w^{*} u h^{*} f t r\right) /\left(2.3 .1415926^{*} r w^{*} u h^{*} h k 2\right)$

traml=gama*zl+tair-gama*aal+

$1(t 0+$ gama*aal-tair)* $\exp (-2 I / a a I)$

$\operatorname{tram2}=$ gama*21+tair-gama*aa2+

1 (t0+gama*aa2-tair)*exp(-zI/aa2)

c---heat flux

c---qfiux =heat flux into formation, $(w / m * * 2)$

c-m-qtf=total heat flux into formation, $(w)$

c-- $q \mathrm{~cm}=$ total cumulative heat transfer into formation $(\mathrm{kj})$

qfid =omeg $a^{*}(f a 3-f a l)$

qflux $=-h k 2 * d t 0 *$ gfud

if $(k . e q .10) q t f=6.2831853 * r w * h * u h * d t 0 * f a 4$

if(k.eq.10) qcm =62831853*rw* $h^{*} h^{*} d r 0 * u h * f a 5 / v m / 1000$.

print $510, t, t$ real,y3,ft,tdr, ftr

print 520, fal fa2, fa3

print 530,tr1,tr2,tr3,traml,tram2 
print 537,qftud,qfiux

if(k.eq.10) print 539,fa4,qtffa5,qcm

c10 continue

c1000 continue

99 continue

120 format (5x,'beta=',d115;' sigma='d115,' omega=',

1d115,' $\left.x i={ }^{\prime}, d 11.5\right)$

125 format (10x,'formation thermal conductivity $=$ ',e12.4)

126 format (1x,' wellbore heat transfer coef.='e12.5;' formation

1 thermal conductivity $={ }^{\prime}$, e12.5)

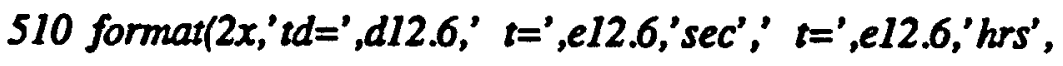

1' $f(t)={ }^{\prime}, e 12.6, '$ td of Ramey=',e12.6,' $f(t)$ of Ramey=',e12.6)

520 format(2x,'tdl=',d12.6,' td2 =',d12.6,' $\left.t d f={ }^{\prime}, d 12.6\right)$

530 format $\left(2 x,{ }^{\prime}\right.$ trl $=^{\prime}$, e12.6,' tr2 =',e12.6,' trf=', e12.6,

I' $\operatorname{traml}={ }^{\prime}, e 12.6, ' \operatorname{tram2}=' e 12.6$ )

33 format $\left(5 x, 3 h z d=, d 12.7,5 x,{ }^{\prime} z={ }^{\prime}, d 12.7, m^{\prime}\right)$

537 format (II,2x;'HEAT FLUX',e12.6,' qfiux=',e12.6,' w/m*m')

539 format (5x,'fiuxd=',d13.7,' total flux=',e13.7;' w'; qcmd=',

Id13.7,' cumulative rate $={ }^{\prime}$, e13.7,' $\mathrm{kJ}$, , II)

199 consinue $\mathrm{c}$

c-.-calculation of exact solution in real space integral

c

goto 1000

epsabs $=0 . e 0$

epsrel $=1 . e-5$

$a a=0 . e 0$

c exactl $=x 01$ aaf $(a)$

inf $=1$

kount $=0$

ifail $=1$

print 9998,aa,epsabs,epsrel

call d01 amf(fst,aa,inf,epsabs,epsrel,result,abserr,w,800

1,iw,102,ifail)

print 9997,result,abserr,kount,iw(I), ifail

$t b w=r e s u l t * d t 0+t x y$

print 9995,tbw 
c ex=abs(exactl-result)

c print 9996,ex

1000 continue

10 continue

stop

9998 format(1h, 2x,1ha,6x,'-lower limit of integration =',

1 10.4/Ih, 2x,3hinf,4x,'-upper limit of integration =',

2 8hinfinity/1h, $2 x$, epsabs - absolute accuracy requested',

$32 h=, e 9.2 / 1 h, 2 x$,'epsrel - relative accuracy requested',

$42 h=, e 9.21)$

9997 format(1h,2x,'result - approximation to the integral =',

1 e14.5/1h, 2x,' abserr - estimate of the absolute error =',

2 el0.3/1h, $2 x$,' kount - number of function evaluations =',

3 i4IIh ,2x,'iw(1) - elements of real workspace used =',

4 i4/Ih, 2x,'ifail - error flag =',i4l)

9996 format(1h,7x,' - exact absolute error =',e10.3)

9995 format(5x,'wellbore temperature =',e125)

end

c

c--numerical Laplace inversion by the Stehfest algorithm

c

subroutine linv $(v, n)$

implicit double precision $(a-h, 0-2)$

dimension $\mathrm{g}(50), \mathrm{v}(50), h(25)$

$g(1)=1 . d 0$

$n h=n / 2$

$n=n h^{*} 2$

do $70 i=2, n$

$g(i)=g(i-1) * i$

70 continue

$h(1)=2.80 / g(n h-1)$

c $f i=i$

do $3 i=2, n h$

$f=i$

if(i.eq.nh) go to 2

$h(i)=f i^{* *}(n h) * g(2 * i) /(g(n h-i) * g(i) * g(i-I))$ 


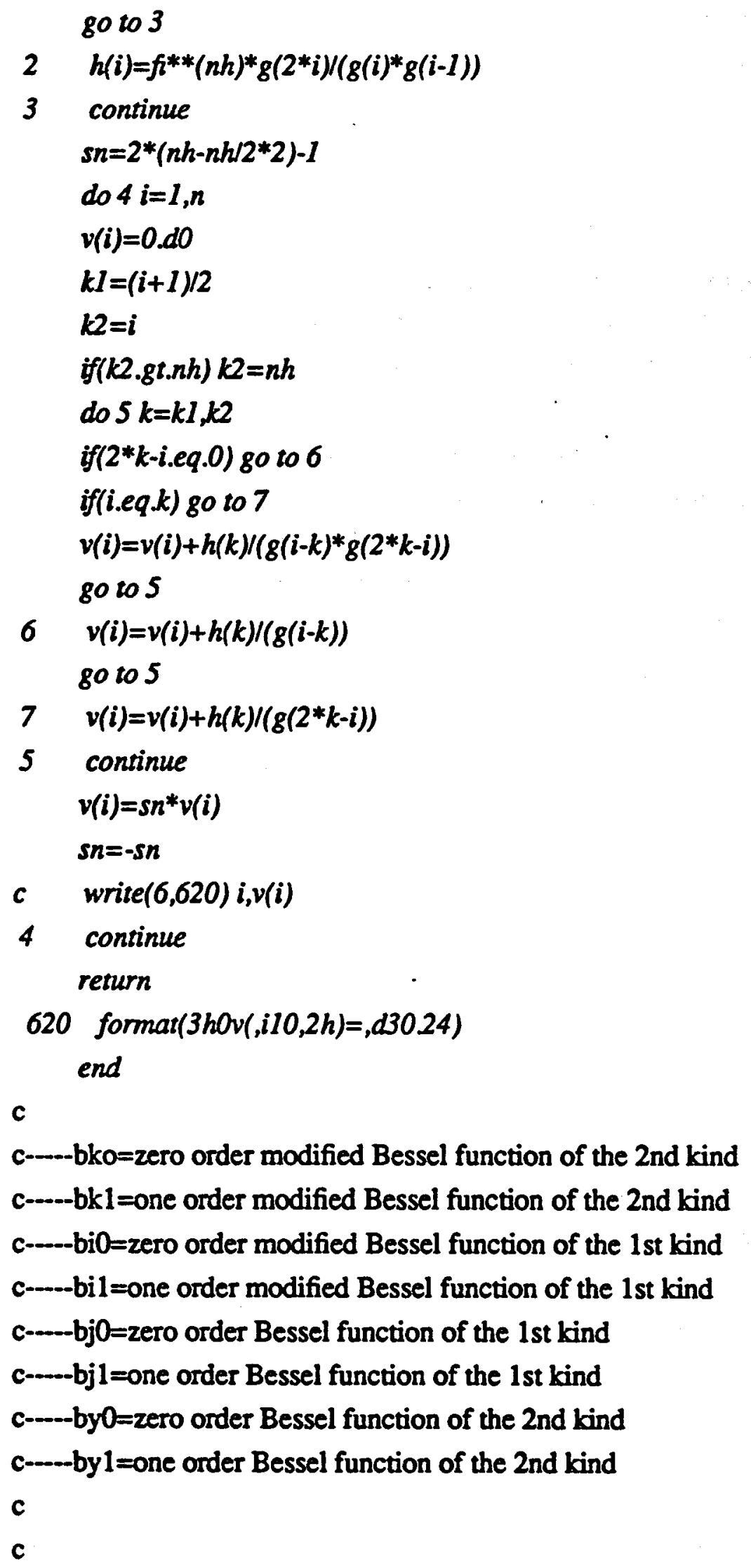


double precision function bkO(x)

external bio

double precision $x, t, t t, b i 0$

$t=5^{*} x$

$\pi=1 / t$

if $(x . l e .2)$ bko $=-d \log (t) * b i 0(x)-57721566+$

$1.4227842 * t * 2+23069756 * t * 4+.0348859 * t * * 6+$

$2.00262698 * t * * 8+.0001075 * t * * 10+.0000074 * t * 12$

if $(x . g t .2)$ bk0 $=\operatorname{dexp}(-x) *(125331414-.07832358 * t t$

$1+.02189568 * t * * 2-.01062446 * t * * 3+.00587872 * t * * 4-$

$\left.2.0025154 * t t^{* * 5}+.00053208 * t * * 6\right) / d s q r t(x)$

return

end

double precision function bkI $(x)$

external bil

double precision $x, t, t t, b i l$

$t=5^{*} x$

$t t=1 \mathrm{~d} t$

if $(x . l e .2)$ bk1 $=d \log (t) * b i l(x)+(1 .+.15443144 * t * * 2$ -

$1.67278579 * t * * 4-.18156897 * t * * 6-.01919402 * t * 8-$

$2.00110404 * t * * 10-.00004686 * t * * 12) / x$

if $(x . g t .2) b k 1=d \exp (-x) *(1.25331414+23498619 * t t-$

$1.0365562 * t t^{* * 2}+.01504268 * t t^{* * 3-.00780353 * t t * 4+}$

$2.00325614 * t t * 5-.00068245 * t * * 6) / d s q r t(x)$

return

end

double precision function biO(x)

double precision $t, t t, x$

$t=x / 3.75$

$t t=I \cdot / t$

if(x.le.3.75) biO $=1 .+3.5156229 * t * 2+3.0899424 * t * * 4+$

$112067492 * t * 6+.2658732 * t * 8+.0360768 * t * * 10+$

$2.0045813 * t * 12$

iff(x.gt.3.75) bi0 $=d \exp (x)^{*}(.39894228+.01328592 * t t+$

$1.00225319 * t * * 2-.00157565 * t * * 3+.00916281 * t * * 4$ -

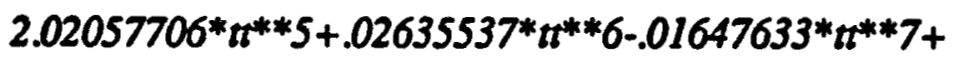




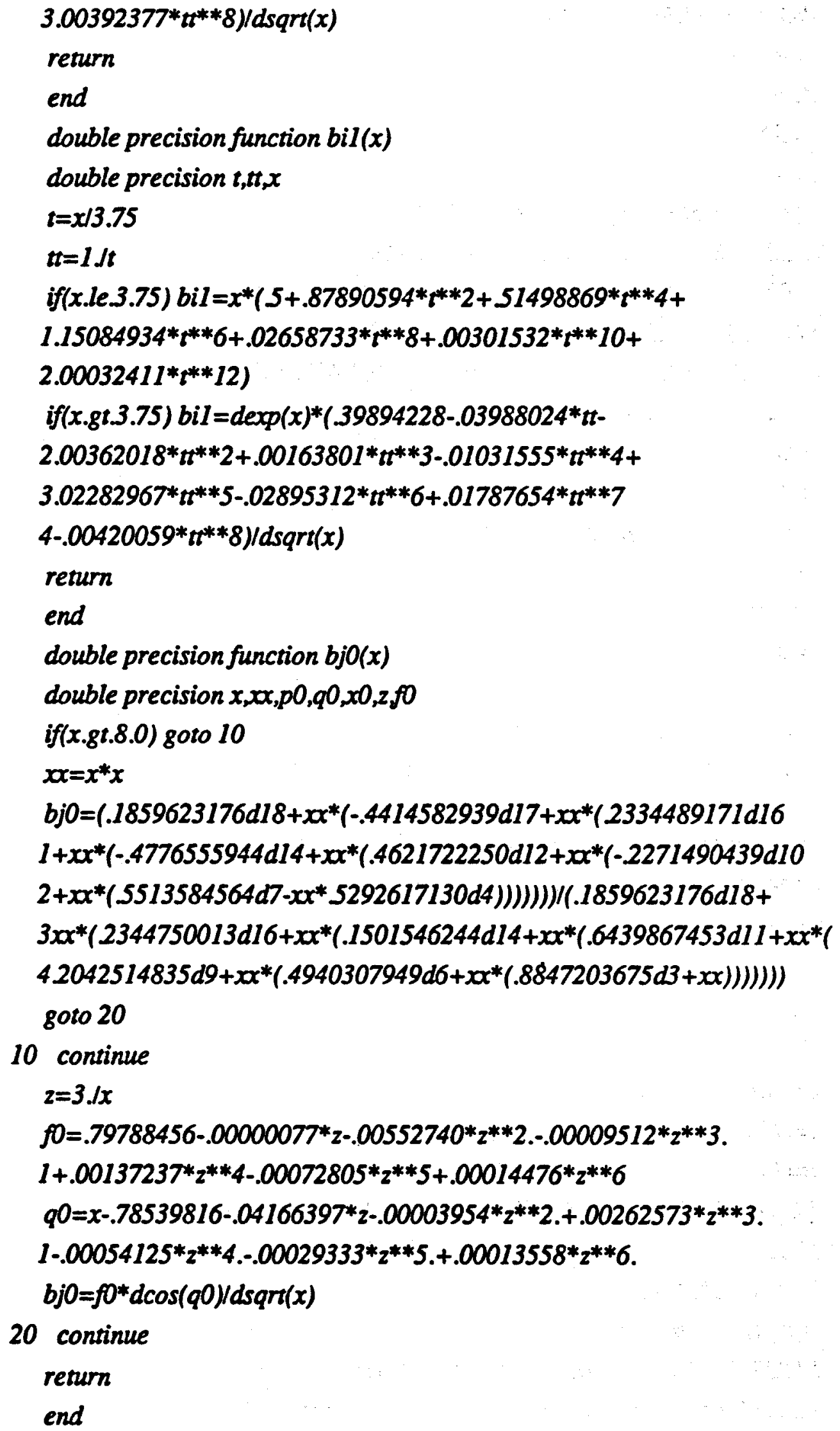


double precision function bjl(x)

double precision $x, x x, p 1, q 1, x 1,2, f 1$

if $(x . g t .8 .0)$ goto 10

$x x=x^{*} x$

$b j 1=x^{*}\left(\left(-3765461244 d 17+x x^{*}\left(-.4187039893 d 16+x x^{*}(.1348155397 d 15\right.\right.\right.$

$1+x x^{*}\left(-.1819933750 d 13+x x^{*}\left(.1166488768 d 11+x x^{*}(-.3533574266 d 8\right.\right.$

$\left.\left.\left.\left.\left.2+x x^{*} .4102013963 d 5\right)\right)\right)\right)\right)\left(.7530922489 d 17+x x^{*}(.1039573325 d 16\right.$

$3+x x^{*}\left(.7342198871 d 13+x x^{*}\left(.3503683946 d 11+x x^{*}(.1250125523 d 9+\right.\right.$

$a x *\left(3451789642 d 6+x x^{*}(\right.$

$4.7209838885(3+x x))))))$ )

goto 20

10 continue

$z=3.1 x$

$f l=.79788456+.00000156 * z+.01659667 * z * * 2 .+.00017105 * z * * 3$.-

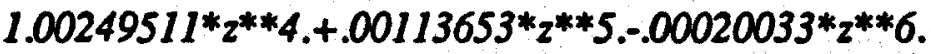

$q 1=x-2.35619449+.12499612 * z+.00005650 * 2 * * 2.0 .00637879 * z^{* * 3}$.

$1+.00074348 * z * * 4 .+.00079824 * z * * 5 .-00029166 * z * * 6$.

$b j 1=f 1 * d \cos (q 1) / d s q r t(x)$

20 continue

return

end

double precision function by $0(x)$

external bjo

double precision $x, x x, x 0, z, b j 0, a y 0,0, q 0$

if(x.gt.8.0) goto 10

$x x=x^{*} x$

ay $0=\left(-.1409469272 d 16+x x^{*}\left(3369788123 d 16+x x^{*}(-2541519322 d 15\right.\right.$

$1+x x^{*}(5917069715 d 13+x x *(-5702858885 d 11+x x *(2396452768 d 9-$

$\left.\left.\left.\left.\left.2 x x^{*} 3653561318 d 6\right)\right)\right)\right)\right)((.1909738817 d 17+x *(2983962232 d 15+$

$a x *\left(2413002405 d 13+x x^{*}(.1337173302 d 11+\right.$

$3 x x^{*}\left(5642518238 d 8+x x^{*}\left(.1890854778 d 6+x x^{*}(.4968451971 d 3+x x)\right)\right)$

4)))

by $0=a y 0+b j 0(x) * d \log (x) * .6366197$

goto 20

10 continue

$z=3.1 x$ 


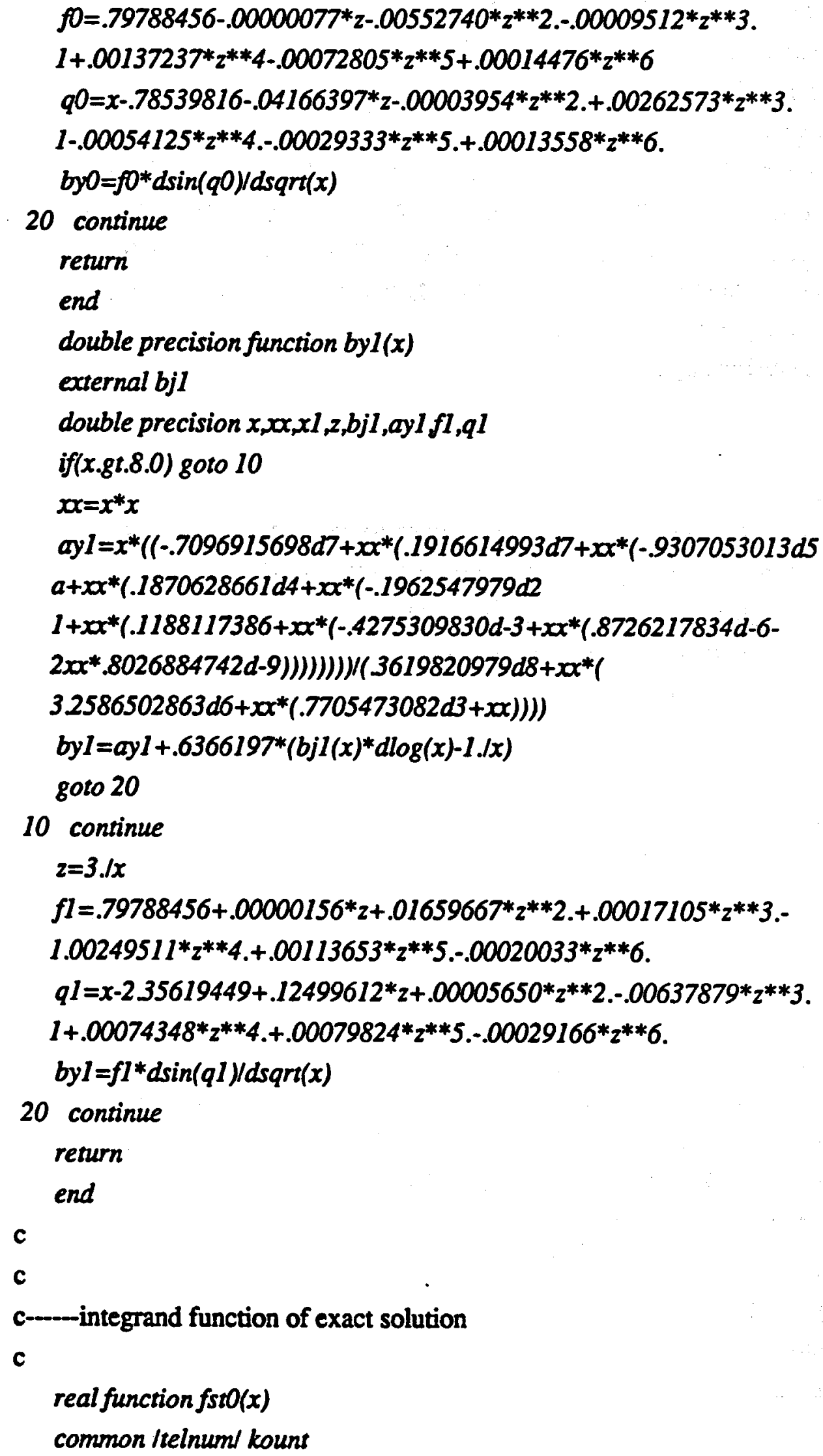


kount $=$ kount +1

$f s t 0=1 . e 0 /((x+1 . e 0) * s q r t(x))$

return

end

c--function of integration

double precision function $f s t(u)$

external bj0,bjl,by0,byl

double precision $x, t, z, b j 0, b j 1, b y 0, b y 1$

double precision beta,xi,omega,sigma

double precision $u, u u, t 1,21$, aj0, ajl, ay 0,ayl, betal,omegal,

1 xil,sigmal ,ep, $r r, d 10, d 11, d d, d 1, d r, z p, y 1, y 2$

common beta,xi,omega,sigma,t,z

common /telnuml kount

kount=kount +1

$u \boldsymbol{u}=\boldsymbol{u}^{*} \boldsymbol{u}$

$x=u$

$t l=t$

$z l=z$

$a j 0=b j 0(x)$

$a j 1=b j 1(x)$

$a y 0=b y 0(x)$

$a y l=b y l(x)$

betal = beta

$x i 1=x i$

omegal =omega

sigmal =sigma

ep $=\operatorname{dexp}\left(-u u^{*} t 1 /\right.$ sigmal $)-1$.

$r r=\left(\right.$ omegal $\left.* a j 0+u^{*} a j 1\right) * a j 0+\left(\right.$ omegal $\left.* a y 0+u^{*} a y 1\right) * a y 0$

d10 $=$ omegal $* a j 0+u^{*}$ ajl

$d 11=$ omegal $* a y 0+u * a y 1$

$d d=(d 10 * d 10+d 11 * d 11))($ betal*omegal $)$

$d l=d d^{*}$ (betal-uu/sigmal)-rr

$d r=d l * d l+.4052847$

$f s t=.4052847^{*} x i 1^{*} d d^{*} e p l\left(u^{*} d r\right)$

iffil.le.21) goto 100

$z p=.6366197^{*} z 1 / d d$ 
-54 -

$y 1=d \sin (2 p)$

$y 2=\exp (z 1 * r r / d d)$

$e p=1 .-\exp (-(t I-z l) * u u /$ sigmal $)$

$f s t=f s t+.6366197^{*} \exp (- \text { betal*zl })^{*}\left(e p^{*} y 1^{*} y 2 / u+x i 1^{*} e p^{*} d d\right.$

$\left.1 * y 2 *(.6366197 * d \cos (z p)+y 1 * d I) /\left(u^{*} d r\right)\right)$

100 continue

return

end 